\title{
Is There Empirical Evidence on How the Implementation of a Universal Basic Income (UBI) Affects Labour Supply? A Systematic Review
}

\author{
Manuela A. de Paz-Báñez*®D, María José Asensio-Coto® ${ }^{\circledR}$, Celia Sánchez-López and \\ María-Teresa Aceytuno \\ Economics Department, Universidad de Huelva, 21071 Huelva, Spain; asensio@uhu.es (M.J.A.-C.); \\ celia@ole.uhu.es (C.S.-L.); maria.aceytuno@dege.uhu.es (M.-T.A.) \\ * Correspondence: depaz@uhu.es; Tel.: +34-959-21-78-33
}

Received: 27 August 2020; Accepted: 11 November 2020; Published: 13 November 2020

\begin{abstract}
The objective of this article is to determine, as conclusively as possible, if the implementation of a Universal Basic Income (UBI) would lead to a significant reduction in the working age population labour supply. If this were true, implementation of a UBI may not be sustainable. To do this, we will compile empirical evidence from studies over the last few decades on the effects of implementation of a UBI on employment. We apply the PRISMA methodology to better judge their validity, which ensures maximum reliability of the results by avoiding biases and making the work reproducible. Given that the methodologies used in these studies are diverse, they are reviewed to contextualize the results taking into account the possible limitations detected in these methodologies. While many authors have been writing about this issue citing experiences or experiments, the added value of this article is that it performs a systematic review following a widely tested scientific methodology. Over 1200 documents that discuss the UBI/employment relationship have been reviewed. We found a total of 50 empirical cases, of which 18 were selected, and 38 studies with contrasted empirical evidence on this relationship. The results speak for themselves: Despite a detailed search, we have not found any evidence of a significant reduction in labour supply. Instead, we found evidence that labour supply increases globally among adults, men and women, young and old, and the existence of some insignificant and functional reductions to the system such as a decrease in workers from the following categories: Children, the elderly, the sick, those with disabilities, women with young children to look after, or young people who continued studying. These reductions do not reduce the overall supply since it is largely offset by increased supply from other members of the community.
\end{abstract}

Keywords: universal basic income (UBI); labour supply; inequality; poverty; sustainability of social policies

\section{Introduction}

Increases in inequality and poverty in recent decades, both in periods of recession and in periods of economic boom, have sparked renewed interest in studies on these topics. More specifically, in the experimentation and access to empirical evidence in the fight against poverty [1,2]. UBI is of particular interest in this endeavour [3]. This is part of the proposals included in the United Nations Sustainable Development Goals for 2030, namely those that refer to inclusive social development.

Studying UBI in its broadest context involves the fields of ethics and philosophy, social studies and psychology, and tackles underlying questions of human dignity, freedom and justice, or the reciprocity principle, in addition to strictly economic questions. It is these latter questions to which this paper addresses itself as it considers three elements worthy of analysis. First, the effectiveness of UBI 
as a means of eradicating poverty and reducing inequality in comparison with other social policies already in operation. The literature in this respect is extensive and overwhelmingly positive, although dissenting voices can be heard. Second, the economic viability of financing UBI. There is, as yet, no consensus in this regard, although there is clear evidence it could be viable with changes to the taxation system and improvements to the efficiency of the welfare services, including the elimination of systemic redundancies without detracting from its quality or scope.

Third, the impact on employment. This issue is of critical importance as, if the implementation of UBI results in a significant reduction in labour supply, it would be impossible to finance the initiative. The relationship between UBI and employment is indeed complex, since not only does the impact on the labour supply need to be taken into account, but also the impact on the labour demand, entrepreneurship, productivity, aggregate demand, innovation and the development of technology, the 4th Industrial Revolution, social participation, power-sharing, the capacity to negotiate, security, instability resulting from poverty and excessive inequality, personal autonomy and satisfaction, health and education. All of these can affect not only the quantity and quality of the labour supply, but also the quantity and quality of the labour demand, along with the productivity, the innovation, and competitivity of companies. In this paper, we focus on the labour supply and how this might be affected by the implementation of a UBI.

We start with Philippe Van Parijs' widely accepted definition of UBI, "a Basic Income is an income paid by a political community to all its members on an individual basis, without means test or work requirement". That is to say, we consider it a periodic cash transfer by the State or corresponding public institution, which is unconditional, universal, individual (not per family), sufficient (at least the minimum required to live), not based on work, taxes or age, long-term or permanent (in principle, for life).

Although UBI has been considered as one of the most appropriate measures to reduce economic poverty and inequality, one of the most frequently referenced disadvantages is the possible negative effect on the labour supply that would make this measure unsustainable. This stems from the widely held idea that the contribution of money to the "poor" promotes "laziness". This idea, among others, was based on the classical economic theory (Ricardo and Malthus primarily) and later the neoclassical and marginalist theory up to the most complex neo-liberal models, which do not question this assumption.

Where does that idea come from? Is there any empirical evidence to support it? The empirical reality underlying all this at the time of the birth of classical economic theory is the experience of Speenhamland in the United Kingdom (1795), which supposedly demonstrated it according to the studies carried out at the time. These studies have subsequently been analysed, showing they had clearly biased diagnoses [4]. In relation to the neoclassical theory, it does not seem certain that it is forceful in this sense, it rather says that it is possible that this effect occurs in some cases, depending on the combination of income and substitution effects. We investigate the current empirical evidence on this UBI/employment relationship as it is relevant to the sustainability of UBI. Although the important question is how its implementation improves the well-being of the population [5], it is necessary to check whether a UBI can be established as a long-term national policy, since, if as some claim, the implementation of a UBI resulted in many people not working, it would make it unfeasible.

For this reason, a systematic review of the empirical evidence is proposed. In the preliminary explorations, we have not found clear evidence that shows a reduction in the labour supply, which forces us to be more precise and careful in order to clarify the whole question at once, defining if the answer is clear, or if it is necessary to continue carrying out more scientific research to clarify it. That is the reason for preparing this systematic review with a key question: Is there any clear empirical evidence that the implementation of a UBI would significantly reduce the labour supply?

The question, together with its answer, is not trivial, given that a considerable decrease in the labour supply would make its application unsustainable despite its positive effects in reducing poverty, inequality, or improving the physical and psychological health of the most disadvantaged population. On the contrary, an increase in the labour supply, the absence of a significant result, or a small reduction, 
especially in some cases (children, the elderly, the sick, etc.) may be one more argument in favour of its implementation. Even more so in the current context, with the 4th Industrial Revolution which could reduce labour demand.

Therefore, the objective of this article is to clarify through scientific evidence, what is the real effect of UBI on the labour market? What do empirical studies tell us? Is there sufficient scientific evidence one way or the other? Can we explain the answers within the important existing casuistry? Can we provide an explanation in this regard?

For this we carry out a systematic review, applying the PRISMA methodology [6] and making this review systematic, objective, and replicable. This will allow us to ensure that all the available evidence is collected and that we provide a thorough analysis of any possible biases. Furthermore, it will allow other researchers to easily verify these issues, reproducing the methodology used, or criticizing it if they believe it was incorrectly applied. One of the key elements for this is transparency. Therefore, the corresponding action protocol has been prepared (Appendix B). It collects all the steps and actions taken (Appendix C), making it clear how the selection and screening of papers, the extraction and summary of results, and the bias analyses at each stage of the paper have been carried out.

Therefore, following the established protocol, we will focus on the empirical studies carried out in the last two decades, during which the economic empirical research on this topic has been most extensively developed, thereby offering us almost all the empirical scientific analyses of interest (we will refer, however, to the previous ones most widely cited despite their methodological limitations, specific to the empirical studies carried out in the USA and Canada in the 70s of the 20th century). Given that the methodologies used in these studies are diverse and with limitations that we must consider, they are also reviewed to contextualize their results.

To achieve our objective, we outline below the specifications that will be considered (see Appendix B). The population included (or participants) is the potentially active population in general. The intervention to implement a UBI is considered, according to the definition of Van Parijs (2004). However, given the difficulty of studying real experiences and experiments of this instrument, we will consider cases of pseudoUBI or instruments that, although not quite UBI as previously defined, contribute aspects of interest to the study. These instruments are: Income from oil profits or other raw materials, normally low and unstable, Negative Income Taxes (NIT). The design of the study: Several methodologies have been considered in the studies selected for this systematic review grouped as follows: Experiences (UBI, NIT, partial UBI), field and laboratory experiments (especially recent UBI and NIT ones), simulations, specifically static behavioural microsimulation.

The large number of UBI-like measures and policies that have been put in place in recent decades has forced us to differentiate and clarify each one to focus on UBI. However, despite these measures having some different characteristics, they do share others. Therefore, we have analysed them since they can bring clarity to our work. This is the case with Conditional Cash Transfers (CCT) and Unconditional Cash Transfers (UCT). They are, similar to the UBI, periodic cash transfers, although they are not universal or permanent and incorporate strong or weak conditionalities. However, the fact that they have been widely implemented in recent decades, both in less developed and developed countries, allows us to draw some conclusions that could be applicable in our case. Something similar, although with greater differences, occurs with lottery winners and opinion polls.

Therefore, in Section 2, we collect a summary of the empirical studies carried out for these similar instruments. Secondly, in Section 3, we offer a review of the methodologies used to perform the empirical analyses of the UBI/employment relationship. This is relevant due to the difficulty of empirically studying an instrument that has not been fully implemented anywhere, therefore, the application of traditional evaluation methodologies is not possible. This will also serve to present the experiences, experiments, field and laboratory tests, and simulations found, as well as the papers selected for our analysis once the corresponding methodology and protocol have been applied. In Section 4, we will 
extract the results of the selected studies and the discussion of the results is presented in Section 5 . Finally, the conclusions are given in Section 6.

We have made a great effort to consider all the available empirical studies that analyse this relationship so that the results are relevant. More than 1200 papers on the UBI/employment relationship have been considered, of which 38 out of 18 specific cases were selected (those that meet the selection criteria). Any country or region of the world that had experiences, experiments, or simulation on the subject, which has been sufficiently empirically analysed has been considered (see Appendix A).

As we will see below, we have not found empirical evidence to support the claim that the implementation of a UBI causes a reduction in the labour supply. Quite the contrary, the most important contribution of this article is that it settles the discussion on the subject, at least for the time being, pending new scientific evidence that could refute it or, more likely, corroborate or qualify and enrich it.

\section{How the Use of Instruments Similar to UBI Affects Employment}

We aim to summarize the effects that other measures similar to UBI have on employment to draw some interesting conclusions about the characteristics they share. Specifically, we refer to both conditional and non-conditional, non-contributory cash transfers and to lotteries, and other instruments that provide life annuities to certain individuals. Finally, the surveys carried out for this purpose are summarized to find out the opinion of the general population and beneficiaries about this effect.

\subsection{Effects of Conditional (CCT) and Unconditional (UCT) Cash Transfers on Employment}

Although there are not many papers that carry out a systematic review of the effects of the implementation of a UBI on the labour supply from an empirical point of view, they do exist for other instruments that have a certain similarity with the UBI, such as conditional and unconditional cash transfer programmes. These measures are now very widespread throughout the world [7], after their proliferation since the 90 s of the last century. Moreover, in recent years, numerous analyses are being carried out on the effects of this type of aid [8]. Given the large number of papers looking at the effects of these measures, including the effects on employment, and also the abundant reviews and compilations of these studies, our goal here is to do a meta-review of the results on the effects on use of these measures.

Therefore, Fiszbein and Schady [9] compiled all the experiences developed with conditional transfers and their effect on consumption, work, education, and health for the World Bank. These are experiences especially in undeveloped countries and with weak conditionalities such as taking children to school or to health checks. The observed result is the improvement of education and health, the reduction of the gender gap and increased consumption. Regarding the effect on employment, this study does not see clear evidence of a reduction in the labour supply, except in child labour, which did decrease (something that was expressly sought). The 2011 World Bank Study [10] achieves similar results for both CCT and UCT. Other analyses of these experiences focused on Latin America also corroborate these results and clarify that it clearly increases participation in the labour market for men and not so clearly in the case for women, while decreasing child labour [11-14].

Gentilini et al. [15] analysed 119 developing countries that have implemented at least one type of unconditional cash assistance program and 52 countries with conditional cash transfer programs for poor households. They found that these transfers have a significant effect on poverty reduction, but did not analyse whether they have an effect on employment. Evans and Popova [16] carried out a study of transfer programs around the world and found no evidence of idleness either. Banerjee et al. [17] analysed the effect on employment in seven controlled trials in developing countries and is conclusive in the statement that it found no systematic evidence that cash transfers discourage employment. There are other authors who studied the differential effect by gender, and although they tend to consider that transfers to women are more effective than to men, the evidence is not definitive. Yoong et al. [18] only found eight studies that studied this difference. 
However, perhaps the most extensive and definitive study was the one carried out by Bastagli et al. [19], which included a systematic review for the years 2000-2015 of all the studies that evaluated cash transfer programs, especially for low- and middle-income countries. After screening thousands of studies, 165 studies were selected corresponding to 56 programs in 30 countries. One of the effects it analysed was on employment. It found a total of 74 of these studies, for 35 programs and 21 countries that were relevant to this topic. This review, which combines 11 systematic reviews, found that it increases the probability that an adult works and increases the number of hours worked per week; in addition to other beneficial effects for individuals and households in relation to poverty, education, health, savings, investment, self-employment, and the vital autonomy or empowerment of women. Although it found insignificant effects in just over half of the studies, the majority of the studies showed positive effects (in participation and intensity) on employment. Only some cases reported negative effects, especially related to child labour (all the studies that considered this group (19) reported reduced participation and intensity of child labour); and, to a lesser extent, the elderly [20], caregivers of people with disabilities, the sick and casual workers; and, in some cases, women with young children and young people who continued studying. In this regard, we can also highlight [21-26].

The long-term effects have also been studied in recent years. In addition, although personal and social conditions are decisive, positive effects are observed in the incorporation of young people and women into the labour market after having benefited from incentives 10 or 12 years previously (see, for example, the summary for Latin America, Abramo et al. [27] (pp. 60-66)). It can be deduced from these studies that the improvement in children's health, education, and development provided by these measures result in greater long-term job opportunities [28].

As a possible explanation for this increase in work activity, Schjoedt [29] noted that instead of using cash transfers to finance idleness, many beneficiaries used the additional income to invest in assets that expanded their employment capacity (for example, a mobile phone to communicate with potential employers or clients more easily, transportation to attend job interviews and meetings, clean clothes, etc.) or to buy tools and basic products such as seeds, fertilizers or yarn, which allowed them to progress from low-wage paid labour to self-employment activities.

Finally, the idea that if the beneficiaries of these benefits are not required to look for a job, they will not do so, is also refuted. People want to live better than the benefit allows, they also prefer to be autonomous and not depend on the bureaucracy and the limitations that these benefits imply.

Therefore, it is clear from the current set of empirical findings from the implemented cash transfer programs that they do not discourage employment. On the contrary, conditional and unconditional non-contributory cash transfer programs are proving effective, not only to reduce poverty and increase well-being, but also for the labour insertion of adults from beneficiary families. No empirical evidence has been found that the contribution of an income to families discourages their participation in the labour market, nor in the number of hours worked, with some exceptions, despite the fact that these programs have problems due to their design that could force the opposite.

Can we extrapolate these findings to UBI? Let's see the differences and their possible consequences:

- These transfers are not universal. Being reserved for the "poor", it causes what has come to be called the "poverty trap" (or "unemployment trap" when it comes to unemployment-related benefits), since in practice they have a "tax" (benefit reduction rate), in addition to transportation costs and other expenses necessary to get to work very close to $100 \%$ and even higher. This would not happen with UBI. Although it can also help to get out of those traps through cash that covers the expenses to go to work: Clothing, transportation, etc. [30].

- High administrative cost and bureaucratic trap: More than $50 \%$ of potential beneficiaries do not request it, due to lack of awareness, inability to process the paperwork, or to avoid stigmatisation [31], which would not happen with the implementation of UBI [32]. Furthermore, the inclusion and exclusion errors are very high [33]. 
- Unconditional Cash Transfers (UCT) are usually aimed at groups that are not in a position to work (transfers per child in some countries, old-age or disability pensions), expressly seeking that these groups (especially children) do not have to work to survive.

\subsection{Effects of Lottery Winners and Crowdfunding on Employment}

Lottery winners have been studied as an approximation to UBI in the sense that it could tell us what happens when someone receives a large lump sum or a lifetime salary. Many of us think the lucky person would stop working. A group of studies have analysed these experiences. Imbens et al. [34] studied the effect on the employment of these people and observed that there was no effect unless the amount received was very large. Other studies showed a similar behaviour. Marx and Peeters [35], for example, studied the annuity winners in Belgium, with no effect on labour supply. More recently in the Netherlands, Picchio et al. [36] found very little impact on labour supply, especially with prizes of less than EURO 500,000, where there was only a notable reduction in hours worked in the first year. Avery et al. [37] and Faraker and Hedenus [38] revealed that a large majority of prize winners who left their jobs returned to the same positions after a holiday period, moved to a different area of employment after receiving additional education or training, or switched to self-employment [39]. Cesarini et al. [40] observed similar results for the Swedish lottery. We can conclude that most of the people who received these incomes did not leave or reduce their paid work, and that most of the behaviour changes in the labour market involved temporary changes or transitions to new forms of employment. Crowdfunding experiences in Germany, San Francisco, or Korea are similar to the lottery. The most notable limitations are the very small size of the sample and the bias that the choice of the sample implies as participation is voluntary.

\subsection{Results of Surveys Carried Out on the Topic}

We analysed the direct opinion of the beneficiaries or the general population through surveys. The most extensive and recent survey (2016 and 2017) on the subject was carried out in the EU for 28 countries [41]. More than 11,000 people were asked their opinion about UBI. This survey, in addition to reflecting the enormous support for UBI by the European population in general (68\% would vote in favour), confirms the idea that most people would not stop working if they had a basic income. Although there is a clear difference in the responses when talking about them or others: Those surveyed responded that it would be a major problem if people wanted to stop working, at $52 \%$, but when directly asked if they would stop working, only $3 \%$ said yes and $8 \%$ said they would work less. In other words, a large percentage thinks that "others" would stop working, but they would not, something that clearly reflects the widespread stereotype in society [42]. No conclusions can be drawn about whether those who do not work would start working and compensate for this small reduction of those who would stop working or work less, although some respondents said they would look for a new job $(7 \%)$, do more volunteer work $(7 \%)$, or get more qualifications $(5 \%)$.

Many other surveys have been carried out over the last decades in different countries, the common denominator is that this instrument is increasingly accepted among the general population. Countries that enjoy a greater universalisation of social benefits stand out, such as northern European countries. A compilation of the surveys can be seen in [43] (pp. 222-225). In the last wave of the European Social Survey (ESS8) with data from 2016/17, a question E36 on the degree of acceptance of the UBI was collected for the first time with similar results: $60 \%$ average acceptance, with large differences between the 23 countries analysed (40,712 responses). However, perhaps the opinion of those who have experienced UBI, is more interesting even if it is incomplete. This is the case of the survey of 1004 program participants in Alaska in 2017 carried out by The Economic Security Project (ESP), which revealed that $64 \%$ of the Alaskan population was in favour of this measure and preferred it despite the fact that it would involve higher taxes. The study did not observe significant differences between respondents from different political points of view or income level. This result is in contrast 
to 1984 , when the measure was still being implemented (29\% in favour, $71 \%$ against the dividend), which seems to show that the more known about it, the more it is valued.

\section{Methodologies Used in the Analysis of the Effects of UBI on Employment}

As we have pointed out above, it is very difficult to evaluate the implementation of a UBI empirically. This is due to the fact that there are no complete and long enough experiences of the sample as we have defined it, so there is no traditional evaluation, as done for other instruments. Only the national implementation of a complete and permanent UBI would allow us to indisputably evaluate its effects, and even in that case, there would be a debate as to whether the results are transferable to other countries. Since this does not currently exist, it is necessary to apply more or less indirect methodologies to find out if there is scientific evidence of the effect of UBI implementation on the labour market. The question that arises here is what those methodologies are and what their limitations are. We can group them into four types: Methodologies used for the study of partial or incomplete UBI experiences, for field experiments, for laboratory experiments and, finally, simulation methodologies. We will see that, despite its limitations, the large amount of evidence is increasingly conclusive. For an analysis of these methodologies see $[5,39,43,44]$.

\subsection{Methodologies Used in Cases of Partial UBI Experiences}

Although we have not found experiences on the application of a UBI as defined above, some partial ones have occurred, limited in time, in the amount and/or in the population involved. Therefore, below, we summarize the experiences for which there are studies that allow us to analyse the effect of the introduction of a UBI on employment: Alaska, Iran, and the Cherokee Nation. In all these cases, a traditional evaluation methodology on observed facts is used, with panel data. Other experiences that would also be in the same category are not considered since they have not been scientifically evaluated in terms of employment or are just ideas that have not been implemented. This is the case in Mongolia, Qatar, Kuwait, UAE, East Timor, and Macao [45].

\section{(a) Alaska}

Perhaps the longest and most similar experience with this measure is one that has been realised in Alaska continuously since 1982. The most important difference is its very low amount (about USD 2000 per year in a single payment) and its concept as a dividend for oil companies' use of the area's resources. The most interesting thing about this experience is its permanent character over time since it started, allowing us to observe the long-term effects. There are numerous studies on this experience, perhaps one of the most complete and recent is by Jones and Marinescu [46], although we can also highlight references [47-50], etc. To do this, they use beneficiary surveys and registry analysis.

(b) Iran

Among the countries rich in oil and other mineral products that have used instruments similar to basic income, only Iran, where an income has been universally provided since 2011, has been scientifically and specifically analysed in relation to employment. The study carried out by Salehi-Isfahani and Mostafavi-Dehzooei [51] was the most complete and significant. There are some differences to UBI, such as, although the recipients are individuals, it is paid to the head of the family for the entire household. In addition, its financing is through the elimination of subsidies on the prices of oil, gas, water, and other public services, ultimately derived from oil wealth, and not through taxation. Lastly, the amount has decreased dramatically in terms of purchasing power in recent years, due to inflation and the corresponding failure to update the amounts (it has gone from USD 45 per person per month in 2011 to USD 5 at the end of 2018).

The deterioration over time of Iran's political, social, and economic circumstances in these years makes the studies of this experience focus only on the 1st year, therefore, it is possible to isolate the 
effect of the UBI from other external elements. Nevertheless, Gauthier and Tabatabai [52] carried out an analysis of 2 years before and 4 years after (we do not include it here, since it does not analyse the effect on employment).

\section{(c) Cherokee Nation}

In this case, the financing comes from the installation of a casino in the Cherokee tribe territory. Its objective was not to establish a UBI, but to distribute the benefits of the casino among the members of the community. Coincidence allowed it to be scientifically studied by a research group that was studying youth in the area. A control group of young white people from nearby rural farms were used [53]. There is another example of a casino financing basic income in Macao (China) whose economy depends on casinos. Every year since 2011 the government distributes an amount between USD 400 and 1200 ( $1 \%$ of its GDP per capita) to each of its permanent residents and a smaller amount to non-permanent residents. The biggest limitation is the lack of commitment for the following years. The effect on employment has not been studied.

\subsection{Methodologies Used in Field Experiments}

There are not many well-documented cases of field experimentation, although now they are beginning to proliferate and, therefore, in a few years we may have stronger evidence. In this case, it is a matter of carrying out scientifically controlled pilot tests to detect what effects such a measure could have in a complex environment such as today's society. The methodologies used are basically: Randomized Controlled Trials (RCT), saturation studies, or a combination of both [5].

In older experiments, there were clear design problems that limited their results, see, for example, [54-56]. However, the most recent ones that have been carried out with all these problems in mind also have limitations due to the very nature of field experiments. In addition to being expensive and slow, we must take into account the Hawthome and the Streetlight effects [5]. Furthermore, the nature of UBI makes experimentation difficult. This is due to the fact that the basic elements of this instrument are contrary to a pilot test by their very nature. That is the case with universality: A sample is always limited in the number of individuals that participate, so you can only see the community effects in a limited way if we use the saturation technique. Permanence: An experiment is always limited in time, in this case, they usually last between 1 and 2 years. Therefore, you cannot see the long-term effects and the person who receives the income does not have the security of continuing to receive it in the future. Only with long-term experiments such as the one that has been carried out in Kenya since 2018, scheduled for 12 years, is it possible to mitigate this problem. Additionally, nor can you see the effects on the tax system, the ability to negotiate labour, or the implications on other macroeconomic or social variables, simulations are usually used for this. However, despite these limitations, experimentation can offer elements of great interest, as we will see below.

The first well-documented pilot experiences are those that took place in Canada between 1974 and 1979 in the city of Manitoba and four others in the USA between 1968 and 1980. The Canadian experiment was abandoned without analysing its effects until Forget rescued it from oblivion in 2005 and analysed the archived documentation [57]. The conclusions regarding employment highlight that, although there is a small decrease in employment in the very young population to continue training and some women with young children who chose to spend more time caring for them, in the rest of the population analysed there is an increase in participation and hours worked, with improvement in other social aspects such as health. Four experiments with similar results took place in the USA at the same time $[43,58,59]$. Here, nine different levels of guarantees and nine other types of marginal taxes were taken into account. Despite the limitations of these experiments (lack of randomness, for example) and that they were not related to UBI but to negative taxes or conditional transfers, we can observe some interesting results.

Widerquist [59] did a detailed analysis of these experiences and their methodological difficulties with a review of 11 studies from 1974 to 1993. In these studies, different results were observed in 
relation to the reduction of participation in and hours of work, ranging from a small percentage for married men (between $0.5 \%$ and $9 \%$ ) to a much larger extent for wives and single mothers (between $0.61 \%$ and $30 \%$ ). In any case, the studies that extrapolated the results to the national level were, for example, for Gay, Indiana by Moffitt [60], and the reduction in the labour supply was a meagre 1.6\%, from $4.5 \%$ [5,59]. The reduction occurs mainly since people of this type (more disadvantaged) who become unemployed take longer to find another job than the national average. What does seem evident is that poverty was reduced and the well-being, health, and incorporation of children into school improved in the most disadvantaged population, which were and are the objectives of this type of program, without causing problems that made it unfeasible, for example, a significant reduction of the national labour force. The biggest problem with these experiments was perhaps poor communication, simplification, and intentional distortion of the results [5].

However, two lessons can be drawn from older experiences: One, how difficult it is to conduct a field experiment with sufficient guarantees, and two, how easy it is to manipulate the data to say what we expect as a result of experimentation and convince public opinion of that result. These problems, among others, aim to overcome the most recent studies that we analyse here.

In recent decades, more controlled and better designed experiences have proliferated, due to the increasingly popular and accepted idea. Below, we collect the experiments selected for analysis and those rejected for different reasons, distinguishing between developed and developing countries, since the results may be different in countries with strong welfare states and countries with weak welfare states.

\subsubsection{Developed Countries}

\section{(a) Finland}

Two thousand unemployed people receiving random unemployment benefits between the ages of 25 and 58 years old were selected to receive USD 560 per month, unconditionally and without means testing, for 2 years (2017-2018), with a control group who did not receive anything, consisting of all the unemployed people who received the same unemployment benefit (173,000 people). A scientific follow-up was carried out to verify that the results were consistent, through RCT. The data was obtained from the record of changes in relation to employment in the period from November 2017 to October 2018, and interviews at the end of the experiment period [61-64].

\section{(b) Ontario (Canada)}

The experiment was designed in 2017 for three specific locations: Hamilton, Brantford, and Brant County, with the intention of applying it to the entire state. However, the experiment was abruptly interrupted by a change of party in the government in August 2018 and the payment of the experiment was stopped in March 2019, abandoning its evaluation. However, the Hamilton Community Foundation has produced an evaluation report of the most relevant results based on an online survey and in-depth interviews with the beneficiaries [65]. The instrument applied was a negative income tax, to 4000 low-income people aged 18 to 64 years old (see the design reference [66-69]).

More field experiments have been carried out and are being carried out in developed countries, which we do not consider here due to the fact that they are experiments that analyse instruments far from a UBI, they are small in the number of people involved, and/or they do not address the issue of employment. This is the case of the experience in Stockton (USA) that was more a demonstration than a scientific experiment. The Oakland case in California with 1000 people and USD 1000 per month to low-income people aged 21 to 40 years old, studies the impact on social and physiological well-being, but not the effect on employment [70]. In Europe, there are experiments in Utrecht and other cities in the Netherlands, Barcelona in Spain, Scotland, Serbia, and Slovenia. All of them are small experiences, some not yet implemented, others not analysed in relation to employment, and all far from a real UBI. In Asia, the case of Korea moves away from a UBI, there are three types of experiments: A subsidy 
to people aged 24 years old [71], income as a lottery, and a basic income on a small local scale (see also [72]). The intention is to start a basic rural income in 2020, which has not yet been implemented. China has also produced some local experience not yet analysed.

\subsubsection{Developing Countries}

It is often argued that the UBI is an instrument that is easier to operate in less developed countries and that it is less expensive to experiment in them due to the low standard of living. In fact, numerous experiments are being carried out, especially in Africa and Asia. Funding mainly comes from development aid from private foundations: The GiveDirectly Foundation in Kenya, donations in Namibia, and from international institutions such as UNICEF in India.

\section{(a) Kenya (2018-today)}

In Kenya, there is an initial experiment highlighted in 2011-2013, in Rarieda District, which mainly refers to an UCT to poor people [73]. This experiment offers favourable results: Increased labour supply and demand, economic growth, and substantial improvements in social welfare. The beneficiaries essentially spent the money to improve their homes, increase consumption, start new businesses, and improve their education [74].

More recently, in 2018, a new experiment started, genuinely about UBI in the Western and Rift Valley of Kenya. It is a large-scale experiment (197 villages plus 100 control villages, 20,000 people) that in reality includes three different experiments: One long-term (12 years: 2018-2030), another medium-term ( 2 years) and, finally, another that gives the amount of 2 years at the beginning in two payments- $\mathrm{KSH}$ 250 (about USD 30 per month; about $25 \%$ of GDP per capita).

The first follow-up survey was carried out in 2019 and another one will be carried out every 3-5 years. The aim is to evaluate the results on different factors: Use of time (work, education, leisure, participation in the community), risk taking (emigrating, starting a business), economic status (income, consumption, assets, food security), gender (empowerment of women), aspirations, and life prospects.

(b) India (June 2011-November 2012)

The Self-Employed Women's Association (SEWA), which groups more than two million members, set up an experiment in India between June 2011 and November 2012, selecting nine villages at random to give all its members an unconditional monthly amount (rupees 200 for adults and rupees 100 for children for the 1st year and rupees 300 and 150, respectively for the 2nd year). In addition, a control group of twelve villages was established. This case has primarily been studied by Davala et al. [75] and Standing [76]. An analysis is made through the RCT, with several rounds of surveys: An initial (census), an intermediate one, another at the end, and one 4 years after it ends (2017).

\section{(c) Namibia (2008-2009)}

This experiment was carried out between 2008 and 2009 by a consortium of churches, unions, and civil society in order to convince the government of the need and virtue of implementing a UBI at the national level in Namibia to reduce poverty and inequality, as well as being a motor of economic activation. It was led by the Lutheran Evangelical Church.

Each person from Otjivero-Omitara (about 1000 in total) was given N\$ 100 (about USD 8), on the condition that they had resided in the area since the previous year and were not over 60 years old with a public pension $[77,78]$. By including the entire population, a potential bias in the choice of participants was avoided and the community effect could be observed through a saturation study. However, there was an objection to this study due to the problems of lack of independence when the promoter team overlapped with the experience evaluation team [79].

A major problem in the last two cases was the meagre amount of contributions, even for those countries and areas of analysis. If a reasonable amount is considered to be $25 \%$ of GDP per capita, in 
these cases they did not exceed $2 \%$ and $4 \%$ of the respective countries [43]. Furthermore, they were launched in places with a weak or non-existent social welfare system other than the retirement pension. Another element to take into account is that the money comes from abroad, therefore, the effect of the tax increase that this measure would require is not observed.

We do not consider Uganda to have had primarily cash transfer experiences $[80,81]$, that it also reveals very positive results in relation to the supply of employment, human capital, and economic growth. Far from promoting idleness, it creates incentives that strengthen autonomy and responsibility, and avoids paternalism and the feeling of stigma (see, for example, [82-85]). Neither do we consider Brazil for the same reason, nor Mexico City, which is an experience for pensioners over 70 years old (then over 68 years old). We also do not consider experiments that have not been designed or have not carried out analyses on the effect on the labour market, such as Zimbabwe, which carried out 1 year of cash transfers [86].

\subsection{Methodologies Used in the Laboratory Experiments}

Experimental laboratory techniques have traditionally been used in the physical and natural sciences. They have not been used in the social sciences, except psychology. However, there is a whole new branch of economics (Experimental Economics) that deals with the methods used by economists to explain or predict the behaviour of economic agents in a controlled institutional environment. It can be used to test public policies or measures, but also to empirically check different theories or look for notable facts [44].

Could we consider laboratory experimentation a solution to overcome the limitations of the methodologies described above? We agree with Falk and Heckman [87] that, at least for now, they can only be considered as complementary and not substitutes for field experimentation techniques. In principle, experimental techniques can serve to test policies, but fundamentally at the individual level. Duffy [88] deals with the subject of macroeconomic experimentation, although the most extensive analyses are based on microeconomic operations with the assumption of representative agents.

This methodology has hardly been used to analyse the UBI, only some examples can be cited despite the fact that in 2006 Noguera and de Wispelaere [56] advanced this technique as the best way to explain and predict the impact of the application of this policy on the different aspects of interest. However, its capacity has not yet been demonstrated due to its limited scope [44].

Perhaps the first of these studies is that of Haigner et al. [89], who performed an experiment with real effort. We can also cite among the few laboratory experiments found, those carried out by Kawagoe [90], who developed three experiments following the behavioural economics methodologies inherited from the experimental methods widely used in psychology. Another experiment regarding entrepreneurship is collected in Chapter 7 of that same book [44]. In all these cases, there is a great discussion about the external validity of the results due to the small number of participants, which is why these results cannot be guaranteed to be reliable. Internal validity can also be disputed due to the design of the experiments themselves, although it is more easily controlled.

\subsection{Methodologies Used in the Simulations}

Given the difficulties of a direct evaluation through experiences or pilot tests, indirect methods of analysis of these effects through simulations have also been used. Given the difficulties of a direct evaluation through experiences or pilot tests, indirect methods of analysis of these effects through simulations have also been used. They are ex-ante evaluation analyses and, therefore, theoretical with data prior to the instrument's own application. Here, we highlight the one based on microsimulation of administrative data (usually referring to taxes and transfers) and on pre-established family budget surveys.

The simulations usually performed and which we contain in this article, consider a neutral application, that is, there are no increases in other taxes for financing beyond changes in income tax rates. Therefore, they normally consider simplifying the financing of the UBI through a fixed tax rate 
for the entire population, leaving the UBI exempt. This would benefit $80 \%$ of taxpayers and only pay more than the $20 \%$ richer of the population. However, ideally, it is to supplement this form of financing with other taxes such as environmental taxes considering that land use and its resources should be paid to all humanity in the form of income or dividend. Taxes on technological capital, taking into account that most of the research is paid or subsidized by States, must be paid for the use and profit of it, wealth tax. Even in recent years, the possibility of financing UBI through data mining, taxing large technology companies, or through the so-called Tobin rate on financial transactions is being raised. Therefore, the tax rate will be lower and, as a result, better accepted. Tax rates below $50 \%$ are estimated. A summary of the discussion on funding can be found in Van Parijs and Vanderborght [43].

The best developed and most used model is EUROMOD, which facilitates working with microdata from all EU countries, with their respective tax and social welfare policies, while working with changes in policies and the measures and parameters that define them (see a large bibliographic compilation in the EUROMOD database). Other experiences that have followed this model are RUSMOND for Russia, RSMOD for Serbia, SOUTHMOND for southern countries, especially Latin America. The World Bank has developed its own system: ASPIRE, which covers 328 surveys and administrative data since 1998 from 124 countries.

The simulation is a widely used and valid method to demonstrate the possibility of financing UBI, as well as the financial effects on people (winners and losers with the simulated changes), accounting or arithmetic, short-term and first tier, results. It can also be used to monitor effects on employment, specifically on work incentives through behavioural microsimulations. The limitations of this method have been highlighted by Figari et al. [91], etc.

Therefore, although microsimulation studies on basic income have been abundant in recent decades, they tend to focus on the effects on poverty and inequality [92], for this they use a simple static or arithmetic microsimulation. Among the positive aspects of this technique is the possibility of introducing into the equation the different forms of financing and other aspects of the implementation of this measure, such as the amount and defining what other measures they replace. In addition, it allows us to determine effects for different types of people and households, raising the representative agent assumption. Perhaps most importantly, it allows us to determine the possible unwanted effects for people who previously received a benefit that would now be replaced.

It is less common to use microsimulation to see the effect on behaviour, for example, on employment. In this case, the limitations are, first, the possibility of drawing conclusions over time from a cross-section model. To avoid this, the simulation is carried out in two stages, where the first one estimates the necessary parameters in a previously determined model or theory, and then applies that theory with the estimated parameters. Normally, the traditional theory of competitive markets is used, which as we know does not correspond to the observed reality. For example, a perfect competition does not come about due to the great difference in power between the actors in contention and the lack of transparency or perfect information. For this, among other reasons, these markets are regulated. Second, since the data is from a specific moment in time and the evaluation is ex-ante, the estimates can only refer to the short or very short term, since the conditions may not be maintained over time, especially if the change is significant, as would happen with the introduction of a UBI. Third, when making individual estimates, it is very difficult to appreciate the community or macro effects, since a UBI can produce changes in other relevant variables in the model: Consumption, investment, inflation, and labour demand that has feedback on the labour supply. In many of these models, it is assumed that employment depends only on the labour supply, when in reality, and more specifically, at the moment when we are living through a radical change in the labour market, demand has a very important weight not appreciated in these models. Even more so, if one considers the effect of the implementation of a UBI, which could cause displacement of unwanted jobs to better ones that would cause an increase in wages and improvements in working conditions in the former and the opposite in the latter, with the consequent effects on the labour supply. Furthermore, it does not take into account other determining factors that could be influencing the decision to participate or not in the labour market, such as the 
possibility of having nurseries or other care services, or the finding that these decisions depend on other factors and motivations, in addition to financial motivation. Here, neither the effects on geographical displacement nor the environment [93] are considered.

To try to offset these limitations, several strategies have been used:

(a) The most prominent is to try to refine traditional models and theories to better reflect reality [72]. Currently, the most widely used labour supply models for this purpose are a combination of the Random Utility Maximization (RUM) model, which use absolute comparisons of the non-marginal utility and Random Utility-Random Opportunities (RURO) models [94]. Others include: Discrete Choice (DC) and Stochastic Dynamic Programming (SDP) models.

(b) Complement microsimulation with general equilibrium macroeconomic models, which introduce price and wage variations when considering consumption and employment demand, although this increases the problems of dependence on traditional theory (see for example [95-97], and more recently $[98,99])$.

(c) Introduce models of multi-agent simulation, Agent Bases Simulation (ABS). These models allow us to go beyond the pure parametric decision of rational individuals by solving a trade-off based on given and fixed preferences, to fully incorporate social interaction and its effects on behaviour [100] (p. 5). The suitability of this type of simulators for the analysis of the possible impact on human behaviour of a UBI and the complexity of the results it produces can be read in detail in the simulation work of González, Noguera, and de Wispeleare [101].

(d) Long-term panel data can be used for an analysis of what would happen in the long-term job offer, in relation to education decisions and job choice. Other proposals discuss the application of Community Operational Research, although we do not know of any examples in this regard.

(e) Finally, other simulation studies apply the game theory [102]. The authors' question is whether the implementation of a UBI can empty the job market by differentiating heterogeneous actors (hard-working, hard-working conditional, lazy, and conditional lazy).

Of all the studies tracked, we have only found enough analyses with notable results for the first option, therefore, it will be for that which we analyse the results in point 4.4. However, we will also try some analyses that combine microsimulation and general equilibrium models as an example of micro/macro results.

Perhaps one of the first works on this subject is that of Scutella [103] for Australia, although the most developed are those elaborated with EUROMOD for European countries. Therefore, we analyse the cases of Germany, Italy, the United Kingdom, and the EU as a whole. We do not consider Sweden (proposal not carried out), nor Spain (although there are studies for the country in general, for Catalonia and for Andalusia, it does not consider the effects on employment), nor do we consider other non-developed countries that do not have results for employment (in the case of Colombia). France, Finland, the Netherlands, Ecuador, and Canada (Quebec) use simulation, but for other non-UBI cash transfer instruments. In any case, the results are consistent with what is observed here.

\section{Results}

We will now summarize the data extracted from the studies according to the empirical methodologies outlined above. We follow the same order as the previous point. To do this, we follow the PRISMA methodology, specified for this work in the corresponding protocol (see Appendix B). After a systematic search and careful screening to avoid bias, the cases and studies that are included in the study were selected (see Appendix A). Table S1 of supplementarily materials contains a summary of the results developed below. 


\subsection{Results of Partial UBI Experiences}

(a) Alaska

Alaska is perhaps the most studied experience. We collect the most significant studies here, since they are scientifically well-designed analyses, address the effect on employment, and are recent. Therefore, Jones and Marinescu [46] demonstrate, after an elaborate empirical analysis, that the population employed full-time has not changed significantly, but the population employed part-time has increased by $17 \%$. In addition, there is an increase in local jobs (labour demand) due to the increase in demand for local products. It is often argued that the lack of incidence in reducing the labour supply is due to the low amount of income. However, studies on the matter for some cash transfers for other programs show that this is not the case $[104,105]$. The analyses by Widerquist and Howard [49], Berman [50], and Goldsmith [47,48] corroborate the results. Feinberg and Kuhn [106] and Bibler et al. [107] observe small setbacks in the short-term if the annual amount increases by USD 1000, especially among women with young children and very low wages, while it rises in men, while labour demand increases.

(b) Iran

Solehi-Isfahani and Mostafavi-Delozooei [51] show that employment grows for the population in general and the population of the poorest $40 \%$ in particular, but decreases for young people between 20 and 29 years old, possibly to continued studying and women losing participation in the already very small labour force (from $12.1 \%$ in 2009 to $10.0 \%$ in 2011), although it grows in some cases and decreases in others. Entrepreneurship also increases.

\section{(c) Cherokee Nation}

There was no noticeable effect on employment, but there was in other aspects such as well-being and health, the consumption of alcohol and tobacco also decreased, and juvenile delinquency declined considerably $[52,108,109]$.

\subsection{Results of Field Experiments}

(a) Finland

The purpose of this study was to check whether basic income improved employment for the unemployed compared to the existing unemployment insurance measures they received. The result was positive: The people who received the UBI were active for 6.63 days more during 2018 than the control group [64], somewhat higher data, but similar to that reflected in the preliminary study for 2017 [63], despite the conditions changing when Finland introduced a general activation system. In any case, work motivation increased slightly rather than decreasing significantly. What is relevant is that it improved well-being, satisfaction with one's life and health, both mental and physical, self-esteem and trust with institutions and with others, however, without side effects that would make it unsustainable. The security of receiving an amount, even a small one, at the beginning of the month, reduces the stress and anxiety of not having enough to eat or pay the bills. Another important effect, according to this experiment, is the reduction of the "bureaucracy trap": Difficulty in requesting aid, delays, and insecurity in receiving it.

\section{(b) Ontario (Canada)}

Ferdosi [65] has revealed several interesting and useful findings. In relation to employment, an improvement in participation in the labour market is revealed. During the interviews, several patterns emerged among the basic income earners who work. A common pattern was for beneficiaries to report moving from low-paying dead-end jobs to jobs with better working conditions and better long-term 
opportunities. For some, receiving a basic income meant they could take a risk with a new job or career. Several took the opportunity to become self-employed. For others, it meant the freedom to leave behind a job where the employment relationship had become toxic and spend time looking for something better.

Several of the interviewees used the security associated with basic income benefits to continue their education in hopes of finding a better job in the future and making a more positive contribution to society. Another common response was that participants revaluated the balance between caring for people and working in low-paying insecure jobs. Some participants decided to use their basic income benefits to spend more time with children who may have special needs and family members.

Additionally, many beneficiaries reported improvements in their physical and mental health, food security, housing stability, financial situation, and relationships, reshaping their living standards, as well as their sense of self-esteem and hope for a better future. Several of the people interviewed only had a marginal connection to the job market as a result of disabilities and other health problems. Receiving a basic income did not result in many of these people finding more jobs. However, these types of participants generally reported better health and well-being. They found it easier to cover existing debts, improve their nutrition, and participate more fully in their communities. Some moved to better accommodations.

(c) Kenya (2018-today)

The preliminary results are very satisfactory, although we must wait for more definitive results from the surveys carried out. Previous UCT analyses also reported very positive results [110].

(d) India (June 2011-November 2012) (2008-2009)

The fundamental results of this experiment are: Increased productive work: $21 \%$ (9\% in control); economic activity increases: $19.4 \%(7.2 \%$ in control), and self-employment $40 \%$ to $62 \%$ ( $35 \%$ in control). Child labour is reduced by $20 \%$ compared to $5 \%$ in the control population.

Other results are: Increased food sufficiency from $52 \%$ to $78 \%$ (59\% to $57 \%$ in control), increased child nutrition from $39 \%$ to $58 \%$ ( $48 \%$ to $58 \%$ in control), increased food consumption, improved health, and $73 \%$ debt reduction $[29,111,112]$.

\section{(e) Namibia}

The results in relation to employment are an increase in work activity and entrepreneurship. In relation to other results: It increases child nutrition, schooling and medical assistance, poverty, and minor crime decrease.

The data confirm what we have been defending here, that the net effect on employment is positive in quantity and quality, although with a small reduction in some groups to improve and increase their human capital. These experiments may overcome some aforementioned drawbacks, such as design problems and the great difference between working conditions and social policies from those carried out in the $60 \mathrm{~s}$ and $70 \mathrm{~s}$ to the present ones. Although the difficulties typical of this type of experiment referred to above will remain.

\subsection{Results of Laboratory Experiments}

Haigner et al. [89] found no significant difference in choices between working options, self-employment, working for the community, or pursuing leisure in the UBI or non-UBI options, with or without taxes, or with the control group. What is significantly reduced is inequality.

From the three experiments carried out by Kawagoe [90], it follows that: The introduction of a UBI increases supply and work incentives, and, moreover, more than a NIT (experiment 1); second, although supply increases all around, it increases more in people with more competitive and individualistic characters (experiment 2); and, last, it does not necessarily follow that there is a liberation effect for the subdued groups, such as women, children, or the disabled (experiment 3 ). 
The limitation and scarcity of these experiments means that these results must be considered with caution. However, it is increasingly considered that experimentation aimed at identifying parameters and mechanisms would be the most useful to resolve the doubts that may still remain for the design and implementation of a UBI [113]. If it is important to know that a policy works, it is more important to know why it works and the mechanisms involved [114].

\subsection{Microsimulation Results}

\section{(a) Australia}

Australia was one of the first countries to run simulations to test the effects of cash transfers on employment. For Scutella [103], the results are highly dependent on the tax rate and its effect on the incentive to work. Participation and the number of hours worked decrease when tax neutrality and very high-income tax rates are imposed, and yet, they rise with more moderate tax rates. It must be taken into account that it supposes that people's motivation to work is only financial, which means that, for example, the participation and working hours of managers and university students decrease due to the tax increase, somewhat unlikely and contrary to empirical evidence.

Creedy and Dawkins [115] also analyse the relationship between taxes, transfers, and their effect on labour supply, observing that increases due to those receiving benefits, which rise despite the fact that taxes are increased (much less in terms of net), could be discouraged from work.

\section{(b) Germany}

The most complete example of UBI microsimulation analysing the effects on employment is the one carried out for Germany by Sommer [116]. In this study, the negative income tax proposal is used as a substitute for the instruments that exist in Germany, both for welfare and for taxes and various tax brackets. The document provides very detailed results for different households and gender conditions, applying a discrete approximation model with random maximization utility to estimate the labour supply curve. It shows that, despite the fact that for different groups the results are different in terms of increasing or reducing the labour supply (different elasticity), the overall net effect is favourable. For single people, the supply of workers increases for both men and women, more in the latter case ( 0.38 and 1.65 points, respectively) and in relation to the number of hours worked, it decreases somewhat in some cases (men with jobs higher than $40 \mathrm{~h}$ and women between 1 and $40 \mathrm{~h}$ ) and increases in others (women over $40 \mathrm{~h}$ ). For couples, however, although the number of workers in general increases, this is due to the increase in the supply of men (1.39 points), but it decreases for women (1.05 points). As for the number of hours they work, it increases in all cases in women and only decreases in men who work more than $40 \mathrm{~h}$ as in the previous case. All this assuming the 'Efficient Wage Hypothesis', which takes into account that the efficiency of wages depends on the worker's real wage (internal wage), the reserve wage, and unemployment, that is, work incentives are only monetary.

Gilroy et al. [117], using the neoclassical theory, reached the same conclusion: The implementation of a UBI instead of the current conditional system in Germany, would eliminate the unemployment trap and increase labour participation, in addition to the positive effects on well-being.

Horstschräer et al. [118], on the other hand, observed differences between the main income earner in the family which increases their labour supply, and the secondary one or ones where there may be greater or lesser supply reductions depending on the scenarios considered. These results are consistent with those found in other studies, although as a limitation reported by the authors themselves, they highlight the lack of appreciation of how much of this time would be devoted to caring for children or training young people. The need to complement this analysis with studies of labour demand is also revealed.

Colombo et al. [119] offered a joint analysis of microsimulation and general equilibrium. Without going into the limitations of the study, it is an interesting exercise to include the effects on labour demand. The results are consistent with other studies, the labour supply for women in couples 
with young children falls and that of men rises, with an appreciable joint effect, although negative in the two scenarios considered $(1.37 \%$ and $1.06 \%)$. By including the general balance, this decrease is further mitigated $(0.95 \%$ and $1.15 \%)$. It should be borne in mind that we are only considering financial incentives and that the measures are financed entirely with taxes on wages and income.

\section{(c) Italy}

Behavioural microsimulation has also been widely applied to Italy mainly due to Ugo Colombino and his team. Therefore, in Colombino et al. [120], the superiority of UBI is demonstrated over other measures to reduce poverty, inequality, and increase welfare in Italy. It does not consider the effect on employment. In Colombino and Narazari [121], it does consider the effect on labour supply and the result is not significant (variation in average hours of work annually for both men (between $-0.1 \%$ and $-0.6 \%$ ) and women (between $-0.1 \%$ and $-2.6 \%$ ). The same results are in [122].

\section{(d) United Kingdom}

For the United Kingdom, the work of Martinelli [123,124] stands out, which offers information on the different levels of income and indicators of financial work incentives: Participation Tax Rate (PTR) and Marginal Effective Tax Rate (METR). It observes that, although the results in general may be ambiguous, they are favourable to a greater incentive to employment in the poorest population (1st and 2nd quintile), especially those who are currently receiving some type of conditional aid due to the elimination of the effects of the poverty, unemployment and bureaucratic traps, and due to the uncertainty of achieving the lost benefit again or submitting to an unaffordable delay [125]. There are also disincentives for women in couples with part-time jobs. Malcolm Torry has also carried out various simulation studies for the UK (EUROMOD has collected 15 documents, the last from April 2020), but does not discuss its relationship with employment.

\section{(e) European Union}

For the EU, we highlight the work of Islam and Colombino [126], with a methodology that uses microsimulation combined with numerical methods, which is also consistent with what was previously said, making clear the preference observed by the UBI and the so-called General Negative Income Tax (GNIT) on the rest of similar measures. Regarding employment, the effects are very low in all cases: It falls slightly in some and rises slightly in other mechanisms and for different countries. It must be borne in mind that one starts from a neutral system with taxes on wages, without considering other less drastic means such as a combination of different taxes that respond better to this change in transfers.

We can also cite another paper by Colombino et al. [127], a comparative analysis of Denmark, Italy, United Kingdom, and Portugal with similar results. The differences found between the behaviour of women in countries with a very high rate of women working with countries where the rate is low, leads us to think that the reduction in labour supply found in the latter is related more to cultural aspects, in addition to part-time and poorly paid jobs.

Lastly, we collect the examples from France and Ecuador that, although they refer to other non-UBI measures, provide elements of interest: France: Canovas et al. [128] applied a Micro-Macro Simulation Model (SYSIFF, 2006) to the French RSA reform (Revenu de Solidarite Active). It is not a UBI, although it has some similarities. The results on employment are positive: Small variations for couples and more significant variations for singles ( $7 \%$ of those who do not work leave unemployment or inactivity and find a stable full-time job). Ecuador: Mideros and O'Donoghue [129] performed a similar exercise with similar results, increases in work incentives for the main income earners in couples, and decreases for secondary earners, usually women. An interesting element to explain the result is that it is not possible to consider leisure as a normal good for people with low incomes since if you do not have the basic needs covered you will hardly be able to think about leisure. Other examples are Finland [62] and the Netherlands [130]. 
In short, despite the limitations outlined in this ex-ante evaluation and dependent on traditional economic theories where only pecuniary incentives are analysed, the results are stubborn and continue to be positive for employment, although it depends a great deal on the starting assumptions and the parameters used in the model. Therefore, these simulated models reflect declines in the labour supply of the second income earners in couples with young children, young people who continue training and children, the elderly, and people with disabilities forced to work to survive. At the same time, increases in supply are observed in singles and couples without small children of both sexes and in the main income earner in couples with young children. The overall effect is positive or slightly negative depending on the design of the measure, its parameters, and the programs it replaces. If it replaces a highly conditional income or with very high tax rates, the labour supply increases. This is the case of the people with the lowest incomes. If financing is not only through employment taxes, but other taxes are also included (on capital, profits, ecological, consumption, etc.), the effect on labour supply is not slightly negative, but clearly positive.

When only economic incentives are used, these models predict a decrease in the labour supply in those who see their income reduced by the increase in taxes, that is, the people who earn the most income (8th, 9th, and 10th decile). Although in reality it seems unlikely that people with a good job and a high salary will stop working to dedicate themselves to leisure, since their income taxes are raised by several points, not even by the second recipient who would have already stopped working for economic reasons before this circumstance. In fact, this has not been ratified in empirical studies.

\section{Discussion}

From the beginning, we have raised the importance of the subject dealt with here and the difficulty of addressing it. Importance since the sustainability and viability of the UBI depends on not fulfilling the negative predictions of those who believe the UBI would cause many people to stop working. The difficulty of dealing with the subject comes from theoretical ambiguity and the difficulty of empirical analysis. Theoretical ambiguity since even the most traditional and simple economic theory does not give a clear answer on the effect of implementing a UBI on the labour supply due to the two possible basic effects (income and substitution) that can act in opposite ways. Due to the different reaction of the various groups and the great heterogeneity of individuals: Employed or unemployed, with primary or secondary jobs, by sex, by type of household, by age, etc., for the different levels of UBI, how it is financed, and which measures it substitutes.

This theoretical difficulty can be overcome through empirical evidence, which leads us to the next difficulty that stems from the fact that it is a measure never fully implemented. Therefore, the evaluation of this policy must be done more or less indirectly. Through the analysis and evaluation of measures with which it has some similar characteristics, by surveys, by partial UBI measures, or through field or laboratory experimentation. The last strategy is simulation.

The task that we have faced in this article is to check whether the analysis of the empirical evidence observed, experimented, or simulated carried out up to now allows us to establish some incontestable, accepted or, at least, clear knowledge for this issue. The systematic review has been rigorous, laborious, and very comprehensive. In addition, the evidence that emerges from it is conclusive.

Therefore, in the first place, we have not found any empirical evidence that the implementation of a UBI causes a reduction in the labour supply that makes it unsustainable in the long term. In strictly scientific terms, no evidence has been found of most of the negative effects attributed to a UBI. Despite the limitations of the methodologies used for these empirical analyses, the results speak for themselves.

Second, we found a slight decrease in the labour supply, in terms of the number of hours worked and participation, in some cases. These cases are usually related to the need to dedicate time to other activities: Basically, care and training. There is also a slight reduction in some cases of the elderly population and in people with disabilities, and a more important decrease in the labour supply of children. We found only one case, in Iran, where the population between 20 and 29 years old reduces 
their labour supply partly to dedicate themselves to training, but it is not clear that another part is not simply dedicated to leisure since they have little attachment to work. However, it is limited and this result has been questioned by subsequent studies. In some cases, there is also a transfer of the working population from poorly paid jobs with poor working conditions to jobs with better conditions and wages, or towards entrepreneurship. This is observed with the strategy of more training and better conditions to be able to negotiate with the employer, as it is not necessary to take any job only to survive.

Third, other evidence has been the activation of people who were not able to relocate, buy clean clothes, and lacked a means of transportation, in addition to not having the constant threat of losing the aid that allows them to survive if they accept a very temporary job. This has increased the labour supply in the adult population of working age in general, both male and female, especially on low incomes. Therefore, increases in labour supply are observed in the underprivileged population in general: Poor ( $40 \%$ of the poorest population) in the Iran experience; minority ethnicities: Alaska Aborigines and Cherokee Indians; unemployed population. The Finnish experiment expressly deals with the effect on the unemployed who already receive a benefit of the same amount, showing that changing a benefit with means of proof for another without means of proof does not decrease employment but increases, refuting the hypothesis defended by some, that by removing control, the unemployed would not seek employment in significant numbers.

The question here is whether the decision to stop participating or participate fewer hours when introducing a UBI is detrimental in all cases. This will depend on factors that must be examined: If that decision is to continue training, for example, this may lead to a greater labour supply and improvements in future productivity. If it is the case of children, the elderly or people with disabilities who are forced to work to survive, or work fewer hours in order to dedicate themselves to care, it could also be functional (improvement of well-being and productivity). There are others who would leave their job to look for another one with better working conditions or to try entrepreneurship with a certain security. Which leaves us with only one case, which in the studies examined we have not found (it is hinted at in only the case of Iran for some young people between 20 and 29 years old), which may not be functional: Those who stop working out of "laziness". In these cases, would they really remain unemployed or would they look for another job, paid or unpaid, that motivates them? Additionally, if in the end, some people are not willing to work, would it not be better if they did not do it and had enough to survive, rather than occupying a job with very low productivity and preventing others who do want to work from doing so, with greater motivation and productivity?

Can the Existing Theory Explain these Results?

The neoclassical economics, as we have indicated above, is ambiguous and does not seem to give an answer, although some changes would allow it to better adapt to reality. For example, the belief that, for low income levels, the assumption that leisure is a normal good cannot be supported [8].

Another important change is that it is not acceptable to consider that the only work motivation is pecuniary. Therefore, at the individual level, the theory of behaviour includes a much richer panoply of psychological motivations to take into account. Behavioural Economics comes from advances in psychology in terms of motivation to act and seek employment beyond mere economic motivations. In fact, several studies from different branches of psychology show that the motivation to work goes far beyond the pecuniary. There are many intrinsic and extrinsic motivations that transcend them: Curiosity, the desire to increase knowledge, improve and expand capacities, promotion of social relationships, social identity, sense of purpose and meaning, social commitment, and social approval. The bibliography here is very extensive since Maslow [131] in 1954 theorized about the hierarchy of needs and motivations. Seen from this perspective, people who receive sufficient income to satisfy their basic survival needs would not lose their motivation to work, but would continue working to achieve goals at a higher level of human aspiration: Social, emotional, self-esteem, belonging, skills development, and self-realization. 
Pech [132], through a behavioural model, analysed the effects of UBI on the intrinsic motivation of workers and their work effort, and predicted a supply transfer of "bad jobs" (which does not provide intrinsic motivation, where salary and labour effort will rise, due to the drop in the labour supply for each salary level) to "good jobs" (which provide intrinsic motivation, for which the labour supply will increase so that wages could decrease, although the effect on work effort will be ambiguous due to this intrinsic motivation). We can highlight the same trend in the works of Gagné and Desi [133] and Thomas [134] for motivation for intrinsic competences, White [135] and Pike [136] for competences and masters, Kirk and Wall [137] for social motivations, and Maestas [138] for retirees who return to work mainly for reasons of purpose, social commitment, and mental stimulation (see [39]). Another group of theories that would support these assessments are the Motivation Crowding Theory, the consumption theory of external positioning (Conspicuous Consumption from Thorstein Veblen in 1899) and, perhaps the most developed, the Prospect Theory [5,132]. All of them differentiate between "good jobs" with intrinsic motivation and "bad jobs" without intrinsic motivation (see also [93]).

At the macro or collective level, it is necessary to take into account the effects on productivity and consumption. Keynesian rooted theories that are based on demand and not only on supply, suggest that UBI will improve local consumption and with it the demand for local employment with effects on the improvement of working conditions and productivity, which would improve wages and with it the labour supply without causing inflation, in principle. This has also been observed in empirical evidence, as we have seen above.

We have also found that the financing methods of UBI affect, but not as much as expected to, increase, or reduce labour supply. The combined elasticity (substitution and income) of the labour supply is very rigid, according to recent estimates and this means that both the winners and losers of income taxes are not greatly affected and maintain their job offer [139]. Another aspect to note is the effect that UBI could have on entrepreneurship and innovation in both large and small businesses and the State Articles $[140,141]$ give us keys on this subject. Evidence of increased entrepreneurship is evident in the experiences and experiments studied in this article, which are developed more widely in [140]. The issue of innovation is more complex to observe, at the empirical level there is very little reference, see, for example [141] as a complete analysis of the different possible implications of the implementation of a UBI in both open and closed innovation, especially in innovation in small and medinas and in the State.

\section{Conclusions}

We have verified in this article that there is no scientific evidence that confirms that a UBI causes a reduction in the labour supply at a general level, but rather the opposite. We have verified that only in particular cases does a small setback occur due to various causes that, to a great extent, improve individual, family, and general conditions of the economy. All this leads us to firmly deny this objection to the implementation of a UBI, despite the limitations of the methodologies in use.

Although it is not the subject of this systematic review, we have also found positive effects in other labour aspects: The improvement in working conditions in the worst jobs seems related to a greater capacity for labour negotiation; the increase in formal employment for lower jobs, especially if this measure replaces conditional transfers, due to the possibility of combining formal employment and benefit. Changes towards better jobs and entrepreneurship have also been observed. Another aspect of interest is the change in labour demand.

All these aspects, however, should be studied in greater depth since the results are not as conclusive as those observed for the job offer. The discussion here has been limited to the specific purpose of the article so as not to lose rigour. It is very likely that in later articles we will carry out an analysis of others topics: Different ways of financing, the theoretical and political aspects involved in relation to the employment, and technology challenger [142]. We are also working on the demand aspects to consider Graeber's "bullshit jobs" [143] and Standing's "precarious" [144]. 
Therefore, in light of the evidence we have gathered, it all shows that UBI is not only an effective instrument to reduce poverty and inequality and improve social welfare, but it is also sustainable in relation to employment. That is, it improves sustainable development and the SDGs, especially through social and economic development. What remains is to make the political decision and once taken, decide on the best way to implement it within the entire set of complementary measures that aim at the well-being of the population, of the entire population. The question must also be which other measures they replace and which they complement. As Widerquist would say, also on this topic, "the devil is in the details" ("caveats" would he say).

Limitations of this article:

Perhaps the biggest limitation we have in studying the effects of UBI is that it has not been fully implemented, but only partially, so we have also had to resort to experiments and simulations, and measures that have some similarity to UBI. The value of this article is that it has tracked more than 1200 papers looking for all known experiences in recent years (last two decades) by selecting all studies that report empirical evidence on the UBI/employment relationship. Older experiments such as those of the 1970s in the USA and Canada, widely studied in literature and discussed here as a background to the most scientifically sound experiments of recent years, are not considered, although collected.

The great value of this article is that it deals with a specific, very defined issue. This allows us to deepen by getting to settle the issue, for now. However, this implies a limitation: A large number of important aspects around UBI that are related and which will need to be taken into account for a broader understanding of the functioning of the UBI are not addressed. This is the case with their relationship to the entrepreneurship discussed in another article of the authors [140], innovation and the 4th Industrial Revolution [141], the financing problems of this measure, and many other social, psychological, ethical, philosophical, and economic aspects that we logically do not address.

Other limitations come from the reality of the empirical works themselves and what they study or do not study. This is the case with the long-term aspects of the UBI on employment. Although these effects have been studied on measures such as conditional cash transfers $[27,28]$, see paragraph 2.1. of this article, there are no known long-term empirical studies for UBI with the exception of the Kenya experiment that began in 2018, which has not yet reported results. The same applies to other aspects only partially addressed from the empirical point of view, such as the relationship with short-term and lifelong human capital formation and the differences in applying UBI early in life or when work habits have been acquired, as well as changes in working conditions with the implementation of this measure, etc.

The 4th Industrial Revolution is linked to a massive decline in demand for labour, especially for routine (unskilled but also skilled) jobs, although there is discussion about it. While some, perhaps most, believe that it will lead to a significant decline in employment (the most cited references are Brynjolfsson and McAfee [145] and Frey and Osborne [146], others believe that, as in previous times, increasing the productivity of these technological improvements will lead to increased employment, if not in the sectors where this increase is occurring, yes in the other sectors that will be affected [147]. What does seem clear is that the effect will be heterogeneous, adversely affecting low- and medium-skilled jobs. This will further polarize the labour market. This has significantly increased interest in UBI in recent years. In this way, we can say that the call for the 4th Industrial Revolution and the fear of its effects on employment is the most conducive to studies and debates about the need to implement a UBI.

Supplementary Materials: The following are available online at http://www.mdpi.com/2071-1050/12/22/9459/s1, Table S1: Summary Results Table of Selected Cases and Studies.

Author Contributions: Conceptualization, M.A.d.P.-B., M.J.A.-C., C.S.-L. and M.-T.A.; formal analysis, M.A.d.P.-B.; investigation, M.A.d.P.-B.; methodology, M.A.d.P.-B., M.J.A.-C., C.S.-L. and M.-T.A.; validation, M.A.d.P.-B., M.J.A.-C., C.S.-L. and M.-T.A.; writing-original draft preparation, M.A.d.P.-B.; writing-review, editing, and supervision, M.A.d.P.-B., M.J.A.-C., C.S.-L. and M.-T.A. All authors have read and agreed to the published version of the manuscript.

Funding: This research received no external funding. 
Acknowledgments: We are grateful to the anonymous reviewers whose insight helped improved the structure and content of this article.

Conflicts of Interest: The authors declare no conflict of interest.

\section{Appendix A}

Table A1. List of cases and studies considered and excluded with the reason for exclusion.

\begin{tabular}{|c|c|c|c|c|}
\hline & & $\begin{array}{l}\text { Considered } \\
\text { (Yes or No) }\end{array}$ & $\begin{array}{l}\text { Reason for } \\
\text { Exclusion }\end{array}$ & $\begin{array}{l}\text { Studies } \\
\text { Considered }\end{array}$ \\
\hline \multicolumn{5}{|l|}{ EXPERIENCES } \\
\hline & Alaska & YES & - & {$[46-50,106,107]$} \\
\hline & Iran & YES & - & [51] \\
\hline & Cherokee Nation & YES & - & {$[53,108,109]$} \\
\hline & Mongolia & $\mathrm{NO}$ & 4 & \\
\hline & Qatar & $\mathrm{NO}$ & 4 & \\
\hline & Kuwait & $\mathrm{NO}$ & 4 & \\
\hline & UAE & NO & 4 & \\
\hline & Macao (China) & $\mathrm{NO}$ & 4 & \\
\hline & East Timor & NO & 5 & \\
\hline \multicolumn{5}{|l|}{ FIELD } \\
\hline \multicolumn{5}{|l|}{ EXPERIMENTS } \\
\hline \multirow{12}{*}{ Developed countries } & USA 70' (four cases) & $\mathrm{NO}$ & 1,6 & \\
\hline & Manitoba (Canada) & $\mathrm{NO}$ & 6 & \\
\hline & Finland & YES & - & {$[63,64]$} \\
\hline & Ontario (Canada) & YES & - & {$[65]$} \\
\hline & Stockton (USA) & NO & 3 & \\
\hline & Oakland (USA) & $\mathrm{NO}$ & 5 & \\
\hline & Utrecht (Netherlands) & $\mathrm{NO}$ & $3,4,5$ & \\
\hline & Barcelona (Spain) & $\mathrm{NO}$ & $3,4,5$ & \\
\hline & Scotland (UK) & $\mathrm{NO}$ & 5 & \\
\hline & Sweden & $\mathrm{NO}$ & 5 & \\
\hline & Slovakia & $\mathrm{NO}$ & 5 & \\
\hline & Korea & NO & 1,5 & \\
\hline \multirow[t]{7}{*}{ Developing countries } & Kenya & YES & - & [110] \\
\hline & India & YES & - & {$[29,75,76,111,112]$} \\
\hline & Namibia & YES & - & {$[77,78]$} \\
\hline & Uganda & $\mathrm{NO}$ & 1 & \\
\hline & Brazil & NO & 1 & \\
\hline & Mexico City & NO & 1 & \\
\hline & Zimbabwe & NO & 1,4 & \\
\hline \multicolumn{5}{|l|}{$\begin{array}{l}\text { LABORATORY } \\
\text { EXPERIMENTS }\end{array}$} \\
\hline & Haigner et al. (2012) & YES & - & [89] \\
\hline & $\begin{array}{l}\text { Kawagoes (2019) (three } \\
\text { cases) }\end{array}$ & YES & - & [90] \\
\hline & Delsen (2019), Chapter 7 & No & 4 & \\
\hline \multicolumn{5}{|l|}{ SIMULATIONS } \\
\hline & Australia & YES & & {$[103,115]$} \\
\hline & Germany & YES & & [116-119] \\
\hline & Italia & YES & & {$[121,122]$} \\
\hline & UK & YES & & [123-125] \\
\hline & France & $\mathrm{NO}$ & 1 & \\
\hline & Spain & $\mathrm{NO}$ & 1,4 & \\
\hline & Austria & $\mathrm{NO}$ & & \\
\hline & Sweden & $\mathrm{NO}$ & 7 & \\
\hline & Netherlands & $\mathrm{NO}$ & & \\
\hline & European Union & YES & & {$[126,127]$} \\
\hline & Finland & $\mathrm{NO}$ & & \\
\hline & Quebec (Canada) & $\mathrm{NO}$ & 1 & \\
\hline & Colombia & $\mathrm{NO}$ & 4 & \\
\hline & Ecuador & YES & & [129] \\
\hline
\end{tabular}


Table A1. Cont.

\begin{tabular}{|c|c|c|c|}
\hline & $\begin{array}{l}\text { Considered } \\
\text { (Yes or No) }\end{array}$ & $\begin{array}{l}\text { Reason for } \\
\text { Exclusion }\end{array}$ & $\begin{array}{c}\text { Studies } \\
\text { Considered }\end{array}$ \\
\hline $\begin{array}{l}\text { Reason for exclusion: } \\
\text { (1) Cases with instrument away from UBI: CCT, UCT, } \\
\text { (2) Cases with non-working-age populations: Childrer } \\
\text { (3) Cases not significant by size or scientific rigor } \\
\text { (4) The effect on employment is not analysed } \\
\text { (5) It is still undeployed or in process with no results } \\
\text { (6) Old cases } \\
\text { (7) Theoretical or declarative exercise }\end{array}$ & $\begin{array}{l}\text { crowdfunding } \\
\text { elderly }\end{array}$ & polls & \\
\hline
\end{tabular}

Appendix B. Protocol for the Systematic Review of the Article Entitled: “Is There Empirical Evidence on How the Implementation of a UBI Affects the Labour Supply? A Systematic Review"

To ensure that we have avoided most of the risks of bias from our systematic review, we have developed a Protocol following the methodological specifications provided by PRISMA-P 2015 [148]. Below is a summary following your checklist.

\section{Administrative Information}

1. Title: Protocol for the Systematic Review of the Article Entitled: "Is There Empirical Evidence on How the Implantation of a UBI Affects the Labour Supply? A Systematic Review". This protocol is not an update.

2. This protocol has not been registered given the lack of records for economic studies. To our knowledge, there is only the PROSPERO registry (www.crd.york.ac.uk/prospero/) that only admits reviews that have to do with health, albeit in a broad way.

3. a. The authors of this protocol are the same as those of the corresponding article: MAPB, MJAC, MTAP, and CSL, under the direction and responsibility of MAPB. Their emails and institutional affiliation are:depaz@uhu.es, asensio@uhu.es, maria.aceytuno@dege.uhu.es, celia@ole.uhu.es, respectively. Their professional affiliation is the University of Huelva (Spain). b. The contribution of each of the authors is: MAPB elaboration, revision, and improvement of this protocol; MJAC, MTAP, and CSL revision, discussion, and improvement.

4. This protocol does not contain amendments. If we need to amend this protocol, we will give you the date of each amendment, describe the change, and provide justification in this section. Changes will not be incorporated into the protocol.

5. This protocol, similar to the systematic review for which it will serve, does not have funding or sponsorship, beyond the institutional link of the authors to the University of Huelva (Spain). This institution does not have any role in this paper.

Introduction

6. The fundamental reason for conducting this systematic review. Although the implementation of a UBI is associated with the reduction of inequality and poverty more effectively and efficiently than with other instruments, in addition to other beneficial aspects for the population, such as the improvement of physical and mental health, self-esteem, etc., one of the most common criticisms that occurs is that its implementation can cause a reduction in the labour supply. This is what the traditional economic theory and some public opinions supposedly say. In relation to the traditional economic theory, specifically the neoclassical theory, it does not seem certain that it is forceful in this sense, rather it says that it is possible that this effect occurs in some cases, depending on the combination of income and substitution effects. In addition, in relation to the public opinion, they do not fail to reflect the so-called "common knowledge" that we should verify scientifically, especially from the empirical point of view given the theoretical ambiguity, since it could reflect stereotypes far from reality. For this reason, a systematic review 
of the empirical evidence is proposed. In the preliminary explorations, we have not found clear evidence that shows a reduction in the labour supply, which forces us to be more precise and careful in order to clarify the whole question at once, defining if the answer is clear or if it is necessary to continue carrying out more scientific research to clarify it. That is the reason for preparing this systematic review with a key question: Is there really clear empirical evidence that the implementation of a UBI significantly reduces the labour supply? The question and with it the answer, is not trivial, given that a considerable decrease in the labour supply would make its application unsustainable despite its positive effects in reducing poverty, inequality, or improving physical and psychological health of the most disadvantaged population. On the contrary, an increase in the labour supply, the absence of a significant result, or a small reduction, especially in some cases (children, the elderly, the sick, etc.) may be one more argument in favour of its implementation. Even more so in the current context, with the 4th Industrial Revolution which could reduce labour demand. Different systematic reviews have been prepared for other similar instruments such as Conditional Cash Transfers (CCT) and Unconditional Cash Transfers (UCT), which provide us with evidence of interest for this study and we will summarize succinctly in the document as if it were a systematic meta-review. However, for the UBI it is much more complex, due to the lack of complete experiences on it and experimentation has its limitations.

7. Objectives. The objective, therefore, of this systematic review is to empirically evaluate whether the implementation of a UBI has the effect of significantly reducing the labour supply and, if so, under what circumstances and under which implementation design. The chosen question, therefore, is: Is there empirical evidence on how the implantation of a UBI affects the labour supply? To achieve our objective, we outline below the specifications that we will take into account. We follow the recommendations of the PRISMA methodology, specifically the PICOS specifications. In this case: The population included (or participants) is the potentially active population in general, which is the population that can work, from any country or group of countries worldwide. We exclude children (children who are not of legal working age), the population which is considered too old to continue working (in most countries over 65), and people with disabilities incapacitated for work. These groups may have people who are working, but it is not usual or desirable. In these cases, the results in relation to a decrease in the labour supply in that population due to the implementation of a UBI, will be considered a positive or functional result. We do include primary or secondary workers, unemployed and inactive, formal and informal, according to studies, unpaid work (reproductive, voluntary, unpaid internships), or for any other reason, of legal and habitual working age. The population will be considered from an individual point of view. However, it will be grouped to better capture the results by age (youth, adults, seniors), gender (male and female), income (high, medium, low), type of work (primary or secondary paid, unpaid care), training, volunteers or unpaid internships, informal work, precarious, unemployed, not working or looking for a job, disabled person who can work), type of household (single, couples, with children, single parent, etc.). The countries and regions of the world to which the studies refer to will also be taken into account if this implies differences: Developed countries, EU, OECD countries; little or medium developed countries: Latin America, Asia, Africa. Intervention: The intervention to implement a UBI is considered, according to the definition of Van Parijs (2004): Rent paid by the community to all its members individually, universally, unconditionally, periodically, and permanently. Some also consider that it must be a minimum amount sufficient to be able to allow each individual to live with dignity. However, given the difficulty of studying real experiences and experiments of this instrument, we will consider cases of pseudoUBI or instruments that, although not quite UBI as previously defined, contribute aspects of interest to the study. These instruments are: Income from oil profits or other raw materials, normally low and unstable, Negative Income Taxes (NIT): It is a similar instrument, but with problems given that the money is paid ex-post and not ex-ante, although financially it costs the same. Conditional Cash Transfers (CCT) or 
Unconditional Cash Transfers (UCT) that have been widely implemented since the 90s of the 20th century, and also widely evaluated, will be taken into account to the extent that they provide relevant information and will be elaborated separately. We will also consider lottery winners, crowdfunding, and opinion polls separately. Comparison: We will consider the comparison with populations that do not receive this intervention (UBI), and also comparisons between different instruments that implemented UBI/CCT, UBI/UCT, UBI/NIT. We also include comparisons between different UBI application parameters, specifically: Amount, taxes, and tax rate necessary for its implementation, as well as measures that it would replace. Results: The results must be specific, in the sense that they must first and foremost be quantified and contextualized. How does it affect the labour supply? Considerable or slight increase, considerable or slight decrease; significant or not; for what type of population, place and date, specific type of intervention, methodology used; can these results be generalized and also determine the validity of these results? Design of the study: Several methodologies have been considered in the studies selected for this systematic review grouped as follows: Experiences (UBI, NIT, partial UBI), field and laboratory experiments (especially recent UBI and NIT ones), simulations, specifically static behavioural microsimulation. We will also consider the following in case it provides any relevant information: Game theory, other simulations, such as general equilibrium simulations. There are some questions to consider in relation to the methodologies used to view the empirical results in relation to the UBI. In principle, as a 100\% UBI has not been implemented anywhere, an ex-post experience evaluation is not possible. For this reason, we accommodate pseudoUBI realities, which we will analyse in this study. In relation to field experimentation, it is also difficult to think that it is possible with this instrument since it includes several aspects that cannot be experienced in principle: As is the case of universality and permanence. Furthermore, it is difficult to see the long-term effects. In relation to laboratory experimentation, there are few and very limited examples, but they will be taken into account in this paper. Finally, problems also arise in relation to simulation. Static microsimulation is of great interest and has been widely used in recent decades for the ex-ante evaluation of public policies considered for implementation, normally static arithmetic simulation is used. However, for the question before us, static or dynamic behavioural microsimulation is necessary, that is less developed and that implies including theoretical assumptions for the estimation, as a first step, of parameters that can then be used to determine that behaviour by applying it to the chosen theory. This is the case here: We need to estimate the elasticity of the labour supply and then simulate the behaviour of the said labour supply. For all the above reasons, the answer to the question is not immediate. Other methods such as game theory or general equilibrium simulation exacerbate this problem. For this reason, here we will not only do a systematic review of empirical studies, but also of methods applied to carry out these empirical studies with the critical analysis of the efficacy and limitations that they pose.

\section{Method}

8. Eligibility criteria. We will consider all empirical studies related to the question, published in peer-reviewed journals that are indexed to define their scientific quality. Therefore, in the first screening, we will discard all studies that have not been subjected to peer evaluation, with some exceptions such as documents from international reference organizations. We especially consider recent studies, conducted in the last two decades (2000-2020). The specific methodologies selected are: Empirical scientific analysis of data resulting from experiences, field experiments, laboratory experiments, and simulations. The English language has been considered as a reference, although complementary searches have also been made in other languages, specifically in Spanish with the same keywords. They are not considered non-empirical, merely declarative or opinion studies, nor those that do not use a scientific method of analysis that clearly identifies their specifications and results. 
9. Sources of information. We consider the 140 databases of publications that the University of Huelva collects in its Columbus-UHU publications metabase, which groups all the important ones (see the complete list at https://guiasbuh.uhu.es/az.php). Other sources from previous searches, the bibliography from other studies and systematic reviews, Google Scholar, the grey literature from international reference organizations (WB, OECD, ILO, ECLAC, IMF, NN, UU) will also be taken into account. To guarantee the literature saturation, we will explore the reference lists of included studies or relevant reviews identified through searching ("cascading search"). We will also search the authors' personal files to ensure that all the relevant material has been captured. Finally, we will distribute a bibliography of the articles included to the systematic review team, and the entire search procedure will be reviewed by them to avoid the risk of search bias.

10. Search strategy. The first exploratory search of individual keywords will be done, specifically, UBI in regard to economics, "basic income", "labour supply", "labor supply". Second, we will look for combinations close to the systematic review question: UBI and "labour/labor supply", "basic income" and "labour/labor supply" in the bibliographic database Columbus-UHU in English and Spanish. Possible systematic reviews will also be searched for in different corresponding databases. More specific searches will be carried out by the methodology used: Experience, laboratory and field experiments, and simulations. Subsequently, these searches will be carried out in Google Scholar following the same guidelines. The search will be updated towards the end of the review, after being validated to ensure that a high proportion of eligible studies are found by any indexed medium and are current.

11. Record of studies

a. Data management. The studies are recorded on an excel spreadsheet shared by the study authors. It specifies all the bibliographic data and the necessary elements to define their eligibility. The CMO chain (context-mechanism-outcome) is also collected in a comprehensive table that allows us to finally collect the entire process in a PRISMA flow diagram. Duplications will be taken into account to be eliminated. Given the volume, nature, and complexity of the data involved, we have not considered it necessary to use a specific systematic review application such as RevMan from the Cochrane Collaboration or more complex ones, for example, the web-based systematic review software, including Distiller Systematic Review (DSR), EPPI-Reviewer, or Trialstat SRS.

b. Selection process. Review authors will independently review titles and abstracts collected by the search based on the inclusion criteria. We will obtain full reports of all titles that appear to meet the inclusion criteria or where there is some uncertainty. We will seek additional information from the study authors when necessary to resolve questions about eligibility. We will resolve the disagreement through discussion. We will record the reasons for excluding studies.

c. Data collection process. Data extraction will be carried out by two independent authors to avoid the risk of bias, and discrepancies will be resolved by discussing them. An excel template will be used for data collection and synthesis. Since no data meta-analysis will be performed, this process and that of the next two processes will be less complex.

12. Data elements. The data to be collected from the results of each study will be summarized in a table with all the detailed information that will be published in the corresponding study appendix. Identification data of the works: Complete bibliographic data, place to which the study refers, years, population involved, specific intervention applied, application design, control population, results obtained, and summarized. Data from the results of the studies: A sheet will be prepared with the disaggregated information on the results of each study for each experience, experiment, or country of the corresponding simulation. In order to be able to compare the results of different studies for the same situation analysed. 
13. Results and prioritization. The results that we are going to record are related to the effects on participation (extension) and the number of hours worked (intensity) in employment. More specifically, we are interested in knowing if it has increased, decreased, or remained the same, with what intensity, and to know if the result is significant. All this for each population group and according to the design of the intervention. Additionally, the rest of the results of the analysed studies will be taken into account in a summarized way: Effect on poverty and inequality, health, well-being, personal autonomy, etc., but especially, the additional results on working conditions and entrepreneurship. It will specify whether the results are at the individual, household, or aggregate level.

14. Risk of bias in individual studies. The risk of bias will be carefully analysed throughout the procedure. Only individual, peer-reviewed studies will be chosen, using proven scientific methods, which will provide quantitative results. The risk of bias analysis will be carried out at both the study and results level. Limitations and additional caution will be taken into account with results of experiences and experiments that have not been published, published in grey literature, or not sufficiently evaluated. The risk of publication bias does not appear to be significant in this case. However, it will still be monitored for other biases.

15. Data synthesis. Does not apply since it is not a meta-analysis of data.

16. Meta-bias(es). Does not apply since it is not a meta-analysis of data.

17. Confidence in the accumulated evidence. It will depend on the evaluation of the risk of bias detected and the robustness or not of the results of the studies. In addition, the proximity or not of the studies to the evaluated intervention will be taken into account, given the difficulty of evaluating complete UBI experiences. It will also depend on the more or less appropriate analysis methods according to the corresponding analysis. In principle, we will differentiate between insignificant and no effect, with slight, medium, and significant effects of reduction or increase in intensive and extensive labour supply. All this will give us an idea of the strength of the evidence.

\section{Appendix C. Summary of the Procedure Used in the Systematic Search and Screening. Bias Analysis}

\section{1st Stage. Search for Systematic Review Papers}

First, the bibliographic databases that we are going to use for the search were selected. To do this, we have used the resources offered by the University of Huelva which, in collaboration with all Spanish universities, the EU and, in general, all universities worldwide, has a combined system of 140 databases containing all the key papers (Columbus-UHU: https://guiasbuh.uhu.es/az.php). From here, the first searches were carried out in April 2020. The keyword searches were in English, although a search was also carried out in Spanish. Studies of other languages have not been taken into account at this initial stage. The publication dates were not taken into consideration in the first stage, then, following the protocol developed, the studies between 2000 and 2020 were selected. First, preliminary control searches were done, using the keywords separately: UBI (in the economic and social sphere, since these acronyms have a different meaning in other areas), "Basic income" and "Labour/labor supply". In this preliminary search, the large number of studies produced on these topics in recent years was verified.

Afterwards, the searches that will be used for the study, which are the confluences of keywords, are carried out, as stated in the protocol:

1. Search for combined terms: UBI and "labour/labor supply", "Basic income" and "labour/labor supply", and their diverse related terms. Moreover, in Spanish. The same searches were also carried out on Google Scholar.

2. Searches on the specific methodologies used in this type of work and their applications to the question of this study: Simulation, microsimulation, experiences, experiments, field and laboratory studies, etc. 
3. Search for grey literature from specific official bodies and other grey bibliographies: $W B, O E C D$, ILO, CEPAL, IMF, NN, UU.

4. Additional studies that come from previous searches, reviews of the bibliographies used in other studies, and the bibliography of the selected articles have been considered. Moreover, from specialized journals and databases: Basic Income Studies, Euromod, Journal of Economic Literature. The experience of this group of researchers has helped make the systematic search exhaustive, it is unlikely that any relevant scientific work is missing.

5. Additional search for other similar instruments: NIT, CCT, UCT, etc.

The search and screening have been carried out and supervised by MAPB, MJAC, MTA, and CSL. This has served to validate the results, avoiding the risk of bias both in the search and screening. An additional search was performed on 31 July 2020, to update the search and recheck that all relevant cases and studies that meet the criteria have been considered. A total of 1256 papers were found.

2nd Stage. Screening and Selection of Cases and Studies

An initial screening was performed to determine that the papers do in fact deal with the subject of the systematic review and to eliminate duplicates. Followed by an analysis of the titles and abstracts and, if necessary, the content, to choose the papers that provide a scientific analysis with empirical evidence.

The final screening and selection was carried out as follows:

1. We began by differentiating between instruments that are UBI and others that are not, even if they are related or similar, in order to exclude them. This is the case with Conditional Cash Transfers (CCT) and Unconditional Cash Transfers (UCT). We have also collected studies on other instruments that are not as similar such as lotteries, crowdfunding, and surveys. We have grouped the bibliography related to these excluded instruments and, given that their similar characteristics can give us information relevant to our purpose, compiled a summary of all the papers on these widely studied instruments, with reviews that group them in relation to their effects on employment. In other words, we have carried out a kind of systematic meta-review that provides very relevant information, which is why it is summarized in Section 2 of the article.

2. Then, we selected the methodologies used in these analyses using a systematic search. A selection and classification of the specific methodologies used in the empirical analysis of the UBI/employment relationship was carried out. For this, we have grouped the methodologies into four groups: Traditional applied to pseudoUBI experiences, RCT and saturation methods applied to field experiments, laboratory experiments with their specific methodologies and, finally, simulations of various types, in particular microsimulation (see Section 3 of the article).

3. Based on this classification, the cases that we are going to consider were selected. For this, the following inclusion criteria were used:

(a) Cases in which a UBI or very similar instruments have been implemented (partial UBI, NIT). We exclude CCT, UCT, lotteries, crowdfunding, and surveys, although we have addressed them in a separate section (Section 2). We also exclude other instruments such as guaranteed basic income, minimum income, guaranteed wages, etc.

(b) Cases that have been carried out and completed. We exclude proposals that were never implemented and unfinished cases, except for duly justified exceptions.

(c) Cases for which one of the selected methodologies has been systematically applied. We do not consider theoretical or declarative exercises or cases of little significance due to size or scientific rigour.

(d) Cases for which the effect on employment has been specifically studied.

(e) Recent cases. Only those carried out and analysed in the last two decades are considered (2000-2020). 
Applying these criteria, we have selected a total of 18 cases out of the 50 analysed (see Appendix A of the article).

4. Finally, we selected the studies that analyse the chosen cases according to the applied methodology. A total of 87 papers were preselected, which were eventually reduced to 38 , once the aforementioned criteria were applied for the selection of cases, now for the selection of studies.

\section{3rd Stage. Extraction of Relevant Data from the Selected Studies}

The extraction of results was carried out following the protocol (Appendix B). We have created a record for each of the cases with the selected studies, where all the data of interest of the context of each case and of the corresponding studies are established: The methodology used, design, implementers, funders, population involved, length of intervention, place, objective of cases and studies, limitations, etc. Second, we have collected the results obtained from the study of the UBI/employment relationship. We have also collected other results of interest from the study. The summary of all this is represented in the Table S1 of supplementary materials.

\section{4th Stage. Results, Discussion, and Conclusions}

Lastly, the results are summarized with their strengths and limitations. We conclude with the most relevant information, its interpretation, and the implications that these results may have for society in general.

\section{Summary of Risk of Bias Analysis}

The risk of bias has been carefully addressed at all stages. In this search, by being exhaustive and very meticulous, always collecting a surplus of studies. For this reason, so many studies are analysed (1256). During the selection and screening, the selection and exclusion criteria have been specified and applied very carefully to the methodologies, cases, and studies, with an independent review by the other authors of the article. In addition, studies that could contradict the dominant results have been intentionally sought out and taken into account. Lastly, at the time of data extraction, the results of the studies have been taken almost literally to avoid interpretations.

We have taken the following precautions to avoid the risk of bias: (1) Follow a specific methodology of Proven Systematic Review (PRISMA); (2) record both the protocol and its application in a transparent way (Appendices B and C); (3) determine and apply the most appropriate selection and exclusion criteria, taking into account the risk of bias at all times; (4) contrast by several researchers of both the applied methodology and the results obtained; (5) transparency will allow other researchers to evaluate the process and results, expressing possible objections.

Finally, the PRISMA checklist has been applied to this systematic review and the corresponding flow diagram created.

\section{References and Notes}

1. Banerjee, A.V.; Duflo, E. Poor Economics: A Radical Rethinking of the Way to Fight Global Poverty; Public Affairs: New York, NY, USA, 2011.

2. Mullainathan, S.; Shafir, E. Scarcity: Why Having Too Little Means So Much; Henry Holt and Company: New York, NY, USA, 2014.

3. Hall, R.P.; Ashford, R.; Ashford, N.A.; Arango-Quiroga, J. Universal Basic Income and Inclusive Capitalism: Consequences for Sustainability. Sustainability 2019, 11, 4481. [CrossRef]

4. Lo Valero, R.; Aguirre, J. El sistema de Speenhamland, el ingreso ciudadano y la 'retórica de la reacción'. Revista Historia América 2010, 143, 117-143. 
5. Widerquist, K. A Critical Analysis of Basic Income Experiments for Researchers, Policymakers, and Citizens; Palgrave: New York, NY, USA, 2018.

6. PRISMA. It Is a Methodology Widely Used in the So-Called "Experimental" Sciences, Less in the Social Sciences. There Are Other Methodologies, as Is the Case of the Campbell Collaboration, Founded in 2000, Twinned with the Cochrane Collaboration, Which Was Founded in 1993, or the EPPI-Centre of the Same Year, but We Have Chosen to Use the Most Widespread and Tested. Available online: http: //www.prisma-statement.org/ (accessed on 10 February 2020).

7. The World Bank identified that in 2018, 552 million people in undeveloped countries have cash transfer from their governments, in Latin America generally conditional and in Africa normally unconditional. But it only covers a weight of $9 \%$ of the total population. See Ivaschenko, O.; Rodríguez Alas, C.P.; Novikova, M.; Romero Robayo, C.; Bowen, T.V.; Zhu, L. The State of Social Safety Nets 2018; World Bank Group: Washington, DC, USA, 2018; Available online: http://documents.worldbank.org/curated/en/427871521040513398/Thestate-of-social-safety-nets-2018 (accessed on 21 July 2020).

8. De Paz-Báñez, M.A.; Sánchez-López, C.; Aceytuno, M.T. The effect of Universal Basic Income on employment: Does reality contradict economic theory? Forthcoming.

9. Fiszbein, A.; Schady, N. Conditional Cash Transfers: Reducing Present and Future Poverty; World Bank Group: Washington, DC, USA, 2009.

10. GEI. Evidence and Lessons Learned from Impact Evaluations on Social Safety Nets; World Bank Group: Washington, DC, USA, 2011.

11. Cecchini, S.; Madariaga, A. Programas de Transferencias Condicionadas: Balance de la Experiencia Reciente en América Latina y el Caribe; Cuadernos de la CEPAL No. 95, LC/G.2497-P; CEPAL: Santiago, Chile, 2011.

12. CEPAL/ILO. Los programas de transferencias condicionadas y el mercado laboral. Coyuntura Laboral en América Latina y el Caribe 2014, 10, 34.

13. ILO. Effects of Non-Contributory Social Transfers in Developing Countries: A Compendium; Working Paper International Labour Office (ILO); ILO: Geneva, Switzerland, 2010.

14. De Hoop, J.; Furio, C.R. Cash Transfers and Child Labor. World Bank Res. Obs. 2014, 29, 202-234. [CrossRef]

15. Gentilini, U.; Honorati, M.; Yemtsov, R. The State of Social Safety Nets; World Bank Group: Washington, DC, USA, 2014.

16. Evans, D.; Popova, A. Cash Transfers and Temptation Goods: A Review of Global Evidence; Policy Research Working Paper WPS6886; World Bank: Washington, DC, USA, 2014.

17. Banerjee, A.V.; Hanna, R.; Kreindler, G.E.; Olken, B.A. Debunking the Stereotype of the Lazy Welfare Recipient: Evidence from Cash Transfer Programs. World Bank Res. Obs. 2017, 32, 155-184. [CrossRef]

18. Yoong, J.; Rabinovich, L.; Diepeveen, S. The Impact of Economic Resource Transfers to Women versus Men: A Systematic Review; Technical Report; EPPI-Centre, Social Science Research Unit, Institute of Education, University of London: London, UK, 2012.

19. Bastagli, F.; Hagen-Zanker, J.; Harman, L.; Barca, V.; Sturge, G.; Schmidt, T.; Pellerano, L. Cash Transfers: What Does the Evidence Say? A Rigorous Review of Programme Impact and of the Role of Design and Implementation Features; Overseas Development Institute: London, UK, 2016; Available online: https://www.odi.org/publications/10505cash-transfers-whatdoes-evidence-say-rigorous-review-impacts-and-role-design-and-implementation (accessed on 4 May 2020).

20. Kassouf, A.L.; de Oliveira, P. Impact Evaluation of the Brazilian Non-Contributory Pension Program Benefício De Prestaçao Continuada (BPC) on Family Welfare. PEP Work. Pap. 2012, 12, 42. [CrossRef]

21. Bosch, M.; Manacorda, M. Social Policies and Labor Market Outcomes in Latin America and the Caribbean: A Review of the Existing Evidence; CEP Occasional Paper No. 32; Centre for Economic Performance: London, UK, 2012; Available online: http://cep.lse.ac.uk/pubs/download/occasional/op032.pdf (accessed on 4 October 2019).

22. Owusu-Addo, E.; Renzaho, A.M.N.; Smith, B.J. The Impact of Cash Transfers on Social Determinants of Health and Health Inequalities in Sub-Saharan Africa: A Systematic Review. Health Policy Plan. 2018, 33, 675-696. [CrossRef]

23. Gilbert, R.; Murphy, N.; Stepka, A.; Barrett, M.; Worku, D. Would a Basic Income Guarantee reduce the motivation to work? An analysis of labor responses in 16 trial programs. Basic Income Stud. 2018, 13. [CrossRef] 
24. Baird, S.; McKenzie, D.; Özler, B. The Effects of Cash Transfers on Adult Labor Market Outcomes. IZA J. Dev. Migr. 2018, 8, 22. [CrossRef]

25. Baird, S.; McIntosh, C.; Özler, B. When the Money Runs Out: Do Cash Transfers Have Sustained Effects on Human Capital Accumulation? J. Dev. Econ. 2019, 140, 169-185. [CrossRef]

26. Gentilini, U.; Grosh, M.; Rigolini, J.; Yemtsov, R. Exploring Universal Basic Income: A Guide to Navigating Concepts, Evidence, and Practices; World Bank: Washington, DC, USA, 2020; Available online: https://openknowledge. worldbank.org/handle/10986/32677 (accessed on 10 July 2020).

27. Abramo, L.; Cecchini, S.; Morales, B. Programas Sociales, Superación de la Pobreza e Inclusión Laboral: Aprendizajes desde América Latina y el Caribe; Book of CEPAL No.155 (LC/PUB.2019/5-P); CEPAL: Santiago, Chile, 2019.

28. Hoynes, H.W.; Schanzenbach, D. Safety Net Investments in Children; NBER Working Paper 24594; National Bureau of Economic Research: Cambridge, MA, USA, 2018; Available online: http://www.nber.org/papers/w24594 (accessed on 10 June 2020).

29. Schjoedt, R. India's Basic Income experiment. Pathw. Perspect. Int. Dev. 2016, 1, 1-8.

30. Dasgupta, P.; Ray, D. Inequality as a Determinant of Malnutrition and Unemployment: Theory. Econ. J. 1986, 96, 1011-1034. [CrossRef]

31. Moffitt, R. An Economic Model of Welfare Stigma. Am. Econ. Rev. 1983, 73, 1023-1035.

32. Kidd, S.; Athias, D. Hit and Miss: An Assessment of Targeting Effectiveness in Social Protection; Working Paper; Development Pathways and Church of Sweden: Nairobi, Kenya, March 2019.

33. Banerjee, A.V.; Niehaus, P.; Suri, T. Universal Basic Income in the Developing World. Annu. Rev. Econ. 2019, 11, 959-983. [CrossRef]

34. Imbens, G.; Rubin, D.; Sacerdote, B. Estimating the effect of unearned income on labor earnings, savings, and consumption: Evidence from a survey of lottery players. Am. Econ. Rev. 2001, 91, 778-794. [CrossRef]

35. Marx, A.; Peeters, H. An unconditional basic income and labor supply: Results from a pilot study of lottery winners. J. Socio-Econ. 2008, 37, 1636-1659. [CrossRef]

36. Picchio, M.; Suetens, S.; van Ours, J.C. Labour Supply Effects of Winning a Lottery. Econ. J. 2018, 128, 1700-1729. [CrossRef]

37. Avery, R.; Harpaz, I.; Liao, H. Work centrality and post-award work behavior of lottery winners. J. Psychol. 2004, 138, 404-420.

38. Faraker, B.; Hedenus, A. Gambling windfall decisions: Lottery winners and employment behavior. UNLV Gaming Res. Rev. J. 2009, 13, 1-15.

39. Torry, M. (Ed.) The Palgrave International Handbook of Basic Income; Palgrave: London, UK, 2019.

40. Cesarini, D.; Lindqvist, E.; Notowidigdo, M.J.; Östling, R. The Effect of Wealth on Individual and Household Labor Supply: Evidence from Swedish Lotteries. Am. Econ. Rev. 2017, 107, 3917-3946. [CrossRef]

41. Dalia Research. Available online: https://daliaresearch.com/blog-31-of-europeans-want-basic-income-assoon-as-possible (accessed on 3 December 2018).

42. In 2018, Duflo, Banerjee and Stantcheva surveyed 10,000 Americans with similar results (49\% said that 'many people' would stop working if there was a UBI of USD 13,000 a year without conditions, but when asked if they would stop working, only $13 \%$ answered yes. This survey has not been published, but it is referred to by the authors). See Duflo, E.; Banerjee, A.V. Economic Incentives Don't Always Do What We Want Them To. The New York Times. 26 October 2019. Available online: https://www.nytimes.com/2019/10/26/opinion/ sunday/duflo-banerjee-economic-incentives.html (accessed on 8 July 2020).

43. Van Parijs, P.; Vanderborght, Y. Basic Income: A Radical Proposal for a Free Society and a Sane Economy; Harvard University Press: Harvard, MA, USA, 2017.

44. Delsen, L. (Ed.) Empirical Research on an Unconditional Basic Income in Europa; Springer Nature AG: Cham, Switzerland, 2019.

45. For a fairly comprehensive compilation of experiences and field experiments on UBI. In Map of Universal Basic Income Experiments and Related Programs; Prepared in the Stanford University Basic Income Lab; 2020; Available online: https://basicincome.stanford.edu/experiments-map/ (accessed on 25 September 2020).

46. Jones, D.; Marinescu, I. The Labor Market Impacts of Universal and Permanent Cash Transfers: Evidence from the Alaska Permanent Fund; NBER Working Paper 24312; NBER: Cambridge, MA, USA, 2018. 
47. Goldsmith, O.S. The Alaska Permanent Fund Dividend: A Case Study in Implementation of a Basic Income Guarantee; Working Paper; Institute of Social and Economic Research, University of Alaska: Anchorage, AK, USA, 2010.

48. Goldsmith, S. The Economic and Social Impacts of the Permanent Fund Dividend on Alaska. In Alaska's Permanent Fund Dividend: Examining Its Suitability as a Model; Karl Widerquist, K., Howard, M., Eds.; Palgrave Macmillan: New York, NY, USA, 2012; Chapter 4.

49. Widerquist, K.; Howard, M. (Eds.) Alaska's Permanent Fund Dividend: Examining Its Suitability as a Model; Palgrave Macmillan: New York, NY, USA, 2012.

50. Berman, M. Resource rents, universal basic income, and poverty among Alaska's Indigenous peoples. World Dev. 2018, 106, 161-172. [CrossRef]

51. Salehi-Isfahani, D.; Mostafavi-Dehzooei, M.H. Cash transfers and labor supply: Evidence from a large-scale program in Iran. J. Dev. Econ. 2018, 135, 349-367. [CrossRef]

52. Gauthier, S.; Tabatabai, T. How incentives matter? An illustration from the targeted subsidies reform in Iran. Soc. Choice Welf. 2019, 52, 97-125. Available online: https://www.parisschoolofeconomics.eu/docs/ gauthierstephane/gauthier_tabatabai_iran_2018.pdf (accessed on 23 June 2020). [CrossRef]

53. Akee, R.; Copeland, W.E.; Keeler, G.; Angold, A.; Costello, E.J. Parents' Incomes and Children's Outcomes: A Quasi-Experiment Using Transfer Payments from Casino Profits. Am. Econ. J. Appl. Econ. 2010, 2, 86-115. [CrossRef]

54. Groot, L. Basic Income, Unemployment and Compensatory Justice; Springer Science+Business: New York, NY, USA, 2004.

55. Marx, A. Basic Income and Empirical Research-A Lottery Financed Social Experiment: An Alternative Proposal for a Basic Income Social Experiment. Rutgets' J. Law Urban Policy 2005, 2, 167-185.

56. Noguera, J.A.; De Wispelaere, J. A Plea for the Use of Laboratory Experiments in Basic Income Research. Basic Income Stud. 2006, 1. [CrossRef]

57. Forget, E. The Town with No Poverty: The Health Effects of a Canadian Guaranteed Annual Income Field Experiment. Can. Public Policy 2011, 37, 283-305. [CrossRef]

58. Munnell, A.H. Lessons from the Income Maintenance Experiments: An Overview. In Lessons from the Income Maintenance Experiments. Proceedings of a Conference Held in September; Federal Reserve Bank of Boston: Boston, MA, USA, 1986; Available online: https://www.bostonfed.org/news-and-events/events/economic-researchconference-series/lessons-from-the-income-maintenance-experiments.aspx (accessed on 28 September 2020).

59. Widerquist, K. A failure to communicate: What (if anything) can we learn from the negative income tax experiments? J. Socio-Econ. 2005, 34, 49-81. [CrossRef]

60. Moffitt, R.A. The Labor Supply Response in the Gary Experiment. J. Hum. Resour. 1979, 14, 477-487. [CrossRef]

61. Kela. From Idea to Experiment: Report on Universal Basic Income Experiment in Finland; Kela Working Paper 106; Kela: Helsinki, Finland, 2016.

62. Kangas, O.; Simanainen, M.; Honkanen, P. Basic Income in the Finnish Context. Intereconomics 2017, 52, 87-91. [CrossRef]

63. Kangas, O.; Jauhiainen, S.; Simanainen, M.; Ylikännö, M. (Eds.) The Basic Income Experiment 2017-2018 in Finland. Preliminary Results; Reports and Memorandums of the Ministry of Social Affairs and Health; Ministry of Social Affairs and Health: Helsinki, Finland, 2019.

64. Kangas, O. Evaluation of the Finnish Basic Income Experiment; Ministry of Social Affairs and Health: Helsinki, Finland, 2020.

65. Ferdosi, M.; McDowell, T.; Lewchuk, W.; Ross, S. Southern Ontario's Basic Income Experience; Hamilton Community Foundation: Hamilton, OH, USA, 2020.

66. Forget, E.L.; Marando, D.; Urban, M.C.; Surman, T. Pilot Lessons: How to Design a Basic Income Pilot Project for Ontario. In Mowat Research; Mowat Centre: Toronto, ON, Canada, 2016.

67. Segal, H. Finding a Better Way: A Basic Income Pilot Project for Ontario. Discussion Paper Submitted to the Ontario Government. 2016. Available online: https://www.ontario.ca/page/finding-better-way-basicincome-pilot-project-ontario (accessed on 28 July 2020).

68. Young, C. Realising Basic Income Experiments in the UK: A Typology and Toolkit of Basic Income Design and Delivery; Royal Society for the encouragement of Arts, Manufactures and Commerce: London, UK, 2018.

69. Ministry of Community and Social Services. Ontario's Basic Income Pilot: Studying the Impact of a Basic Income; Ontario Ministry of Community and Social Services: Toronto, ON, Canada, 2018. 
70. Y Combinator Research. Basic Income Project Proposal; 32; Y Combinator Research: Oakland, CA, USA, 2017.

71. Seong, E. Seongnam youth dividend monitoring report: The survey results. In All That Seongnam Youth Dividend: Basic Income Coming to Near Us; Basic Income Youth Network and Institute for Green Transformation, Ed.; Basic Income Youth Network and Institute for Green Transformation: Seoul, Korea, 2016; pp. 12-37.

72. Yi, G. The effects of Basic Income on labour supply. Korean Soc. Secur. Stud. 2018, 34, 193-218.

73. Haushofer, J.; Shapiro, J. The Short-Term Impact of Unconditional Cash Transfers to the Poor: Experimental Evidence from Kenya. Q. J. Econ. 2016, 131, 1973-2042. [CrossRef] [PubMed]

74. Haushofer, J.; Shapiro, J. Household Response to Income Changes: Evidence from an Unconditional Cash Transfer Program in Kenya; Working Paper; Massachusetts Institute of Technology: Cambridge, MA, USA, 2013; Available online: http://web.mit.edu/joha/www/publications/haushofer_shapiro_uct_2013.11.16.pdf (accessed on 25 May 2020).

75. Davala, S.; Jhabvala, R.; Mehta, S.K.; Standing, G. Basic Income: A Transformative Policy for India; Bloomsbury: London, UK; New Delhi, India, 2015.

76. Standing, G. Why Basic Income's emancipatory value exceeds its monetary value. Basic Income Stud. 2015, 10, 193-223. [CrossRef]

77. Haarmann, C.; Haarmann, D.; Jauch, H.; Shindondola-Mote, H.; Nattrass, N.; Samson, M.; Standing, G. Towards a Basic Income Grant for All: Basic Income Pilot Project Assessment Report; Basic Income Grant Coalition and Namibia NGO Forum: Windhoek, Namibia, 2008.

78. Haarmann, C.; Haarmann, D.; Jauch, H.; Shindondola-Mote, H.; Nattrass, N.; van Niekerk, I.; Samson, M. Making the Difference: The Big in Namibia: Basic Income Grant Pilot Project Assessment Report; Basic Income Grant Coalition: Windhoek, Namibia, 2009; Available online: www.bignam.org/Publications/BIG_Assessment_ report_08b.pdf (accessed on 10 August 2020).

79. Osterkamp, R. The basic incomegrant pilot project in Namibia: A critical assessment. Basic Income Stud. 2013, 8, 71-91. [CrossRef]

80. Blattman, C.; Fiala, N.; Martinez, S. Employment Generation in Rural Africa: Mid-Term Results from an Experimental Evaluation of the Youth Opportunities Program in Northern Uganda; DIW Berlin Discussion Paper 1201; World Bank Group: Washington, DC, USA, 2012.

81. Blattman, C.; Green, E.P.; Jamison, J.; Lehmann, M.C.; Annan, J. The Returns to Microenterprise Support among the Ultrapoor: A Field Experiment in Postwar Uganda. Am. Econ. J. Appl. Econ. 2016, 8, 35-64. [CrossRef]

82. Murray, M.; Pateman, C. (Eds.) Basic Income Worldwide. Horizons of Reform; Palgrave Macmillan: London, UK, 2012.

83. De Wispelaere, J.; Haagh, L. Introduction Basic Income in European Welfare States: Opportunities and Constraints. Soc. Policy Soc. 2019, 18, 237-242. [CrossRef]

84. Haagh, L. The political economy of governance capacity and institutional change: The case of basic income security reform in european welfare states. Soc. Policy Soc. 2019, 18, 243-263. [CrossRef]

85. Jordan, B. Authoritarianism and social policy. Soc. Policy Soc. 2020, 19, 243-254. [CrossRef]

86. Robertson, L.; Mushati, P.; Eaton, J.W.; Dumba, L.; Mavise, G.; Makoni, J.; Schumacher, C.; Crea, T.; Monasch, R.; Sherr, L.; et al. Effects of unconditional and conditional cash transfers on child health and development in Zimbabwe: A cluster-randomised trial. Lancet 2013, 381, 1283-1292. [CrossRef]

87. Falk, A.; Heckman, J.J. Lab Experiments Are a Major Source of Knowledge in the Social Sciences. Science 2009, 326, 535-538. [CrossRef]

88. Duffy, J. Macroeconomics: A Survey of Laboratory Research. In Handbook of Experimental Economics; Kagel, J.H., Roth, A.E., Eds.; Princeton University Press: Princeton, NJ, USA, 2016; Volume 2.

89. Haigner, S.; Höchtl, W.; Jenewein, S.; Schneider, F.G.; Wakolbinger, F. Keep on working: Unconditional basic income in the lab. Basic Income Stud. 2012, 7, 1-14. [CrossRef]

90. Kawagoe, T. Experimental and Game Theoretical Analyses of the Unconditional Basic Income. In Empirical Research on an Unconditional Basic Income in Europa; Delsen, L., Ed.; Springer Nature AG: Cham, Switzerland, 2019.

91. Figari, F.; Paulus, A.; Sutherland, H. Microsimulation and Policy Analysis; Institute for Social and Economic Research Working Paper 2014-2023; University of Essex: Colchester, UK, 2014.

92. Rigolini, J.; Lustig, N.; Gentilini, U.; Monsalve, E.; Quan, S. Comparative Effects of Universal Basic Income: Emerging Issues and Estimates. In Exploring Universal Basic Income: A Guide to Navigating Concepts, Evidence, and Practices; Gentilini, U., Grosh, M., Rigolini, J., Yemtsov, R., Eds.; World Bank: Washington, DC, USA, 2020; Available online: https://openknowledge.worldbank.org/handle/10986/32677 (accessed on 10 July 2020). 
93. Ollinaho, O.I.; Arponen, V.P.J. Incomegetting and Environmental Degradation. Sustainability 2020, 12, 4007. [CrossRef]

94. Aaberge, R.; Colombino, U. Structural Labour Supply Models and Microsimulation; IZA Institute of Labor Economics, Discussion Paper Series No. 11562; Institute of Labor Economics: Bonn, Germany, 2018.

95. IMF. Fiscal Monitor: Tacking Inequality; International Monetary Fund: Washington, DC, USA, 2017.

96. Nikiforos, M.; Steinbaum, M.; Zezza, G. Modeling the Macroeconomic Effects of a Universal Basic Income; The Roosevelt Institute: New York, NY, USA, 2017.

97. Spermann, A. Basic Income in Germany: Proposals for Randomised Controlled Trials Using Nudges. Basic Income Stud. 2017, 12, 271-290. [CrossRef]

98. Daruich, D.; Fernández, R. Universal Basic Income: A Dynamic Assessment; WP NBER 27351; NBER: Cambridge, MA, USA, 2020.

99. Jaimovich, N.; Saporta-Eksten, I.; Siu, H.; Yedid-Levi, Y. The Macroeconomics of Automation: Data, Theory, and Policy Analysis; Centre for Economic Policy Research: London, UK, 2020; Available online: https://cepr.org/active/ publications/discussion_papers/dp.php?dpno=14362 (accessed on 14 July 2020).

100. Noguera, J.A. Percepciones de justicia y conducta laboral. In Renta Básica de Ciudadanía en Tiempo de Crisis; Moreno, G., Barragué, B., Eds.; Universidad del País Vasco: Bilbao, Spain, 2009.

101. González, S.; Noguera, J.A.; de Wispeleare, J. The Provision of a Basic Income as a Collective Action Problem. In Proceedings of the II Jornada de Sociología Analítica y Diseño Institucional, Barcelona, Spain, 3-4 November 2009.

102. Tena-Sánchez, J.; Noguera, J.A. Renta Básica e incentivos laborales: Una aproximación desde la teoría de juegos. Revista de Ciencias Políticas 2016, 36, 563-582. [CrossRef]

103. Scutella, R. Moves to a Basic Income-Flat Tax System in Australia: Implications for the Distribution of Income and Supply of Labour; Working Paper 5/04; Melbourne Institute of Applied Economic and Social Research: Melbourne, Australia, 2004.

104. Burtless, G. The work response to a guaranteed income: A survey of experimental evidence. Fed. Reserve Bank Boston Conf. Ser. Proc. 1986, 30, 22-59.

105. Novella, R.; Ripani, L.; Cruces, G.; Alzúa, M.L. Conditional Cash Transfers, Female Bargaining Power and Parental Labour Supply. IDB Working Paper 368. 2012. Available online: https://pdfs.semanticscholar.org/ af7d/e490c3d6243ea65a2335909d0e42ce8dfc7a.pdf (accessed on 13 July 2020).

106. Feinberg, R.; Kuhn, D. Guaranteed Non-Labor Income and Labor Supply: The Effect of the Alaska Permanent Fund Dividend. BE J. Econ. Anal. Policy 2018, 18. [CrossRef]

107. Bibler, A.; Guettabi, M.; Reimer, M. Short-Term Labor Responses to Unconditional Cash Transfers; Working Paper; Institute of Social and Economic Research: Anchorage, AK, USA, 2019.

108. Costello, E.J.; Erkanli, A.; Copeland, W.; Angold, A. Association of Family Income Supplements in Adolescence with Development of Psychiatric and Substance Use Disorders in Adulthood among an American Indian Population. JAMA J. Am. Med Assoc. 2010, 303, 1954-1960. [CrossRef]

109. Marinescu, I. No Strings Attached: The Behavioral Effects of U.S. Unconditional Cash Transfer Programs; Roosevelt Institute: New York, NY, USA, 2017.

110. Egger, D.; Haushofer, J.; Miguel, E.; Niehaus, P.; Walker, M. General Equilibrium Effects of Cash Transfers: Experimental Evidence from Kenya. Unpublished Working Paper. 2019. Available online: https://www. givedirectly.org/ubi-study/ (accessed on 3 April 2020).

111. Davala, S.; Jhabvala, R.; Standing, G.; Badgaiyan, N. Piloting Basic Income: A Legacy Study. Final Report; SEWA Bharat and INBI: New Delhi, India, 2017.

112. SEWA Bharat. A Little More, How Much It Is ... Piloting Basic Income Transfers in Madhya Pradesh, India; SEWA Bharat: New Delhi, India, 2014; Available online: http:/sewabharat.org/resources/publicationsandreports/ (accessed on 20 July 2020).

113. Hoynes, H.W.; Rothstein, J. Universal Basic Income in the US and Advanced Countries. Annu. Rev. Econom. 2019, 11, 929-958. [CrossRef]

114. Rothstein, J.; Von Wachter, T. Social Experiments in the Labor Market. In Handbook of Economic Field Experiments; Duflo, E., Banerjee, A.V., Eds.; Elsevier: Amsterdam, The Netherlands, 2017; Volume 2, pp. 555-637.

115. Creedy, J.; Dawkins, P. Comparing tax and transfer systems: How might incentive effects make a difference? Econ. Rec. 2002, 78, 97-108. [CrossRef] 
116. Sommer, M. A Feasible Basic Income Scheme for Germany: Effects on Labor Supply, Poverty, and Income Inequality; Springer: Heidelberg, Germany, 2016.

117. Gilroy, B.M.; Heimann, A.; Schopf, M. Basic Income and Labour Supply: The German Case. Basic Income Stud. 2013, 8, 43-70. [CrossRef]

118. Horstschräer, J.; Clauss, M.; Schnabel, R. An Unconditional Basic Income in the Family Context: Labor Supply and Distributional Effects; Discussion Paper 10-091; ZEW Center for European Economic Research: Mannheim, Germany, 2010.

119. Colombo, G.; Schnabel, R.; Schubert, S. Basic Income Reform in Germany: A Microsimulation-AGE Analysis. Available online: https://www.aiel.it/page/old_paper/colombo.pdf (accessed on 5 June 2020).

120. Colombino, U. Five Issues in the Design of Income Support Mechanisms: The Case of Italy; Institute for the Study of Labor (IZA): Bonn, Germany, 2011; Volume 6059.

121. Colombino, U.; Narazari, E. Designing a Universal Basic Support Mechanism for Italy: An Exploratory Tour. Basic Income Stud. 2013, 8, 1-17. [CrossRef]

122. Colombino, U. Five Crossroads on the Way to Basic Income. An Italian Tour. Ital. Econ. J. 2015, 1, 353-389. [CrossRef]

123. Martinelli, L. Exploring the Distributional and Work Incentive Effects of Plausible Illustrative Basic Income Schemes; IPR Working Paper; Institute for Policy Research: Bath, UK, 2017.

124. Martinelli, L. The Fiscal and Distributional Implications of Alternative Universal Basic Income Schemes in the UK; IPR Report; Institute for Policy Research: Bath, UK, 2017.

125. Kalliomaa-Puha, L.; Tuovinen, A.K.; Kangas, O. The Basic Income Experiment in Finland. J. Soc. Secur. Law 2016, 23, 75-88.

126. Islam, N.; Colombino, U. The case for NIT+FT in Europe. An Empirical Optimal Taxation Exercise. Econ. Model. 2018, 75, 38-69.

127. Colombino, U.; Locatelli, M.; Narazani, E.; O’Donoghue, C. Alternative Basic Income Mechanisms: An Evaluation Exercise with a Microeconometric Model. Basic Income Stud. 2010, 5, 1-31. [CrossRef]

128. Canova, L.; Piccoli, L.; Spadaro, A. An ex ante evaluation of the Revenu de Solidarité Active by micro-macro simulation techniques. IZA J. Eur. Labor Stud. 2015, 4, 17. [CrossRef]

129. Mideros, A.; O'Donoghue, C. The Effect of Unconditional Cash Transfers on Adult Labour Supply: A unitary discrete choice model for the case of Ecuador. Basic Income Stud. 2015, 10, 225-255. [CrossRef]

130. Jongen, E.; de Boer, H.W.; Dekker, P. MICSIM-A Behavioural Microsimulation Model for the Analysis of Tax-Benefit Reform in the Netherlands; CPB Background Document; CPB Netherlands Bureau for Economic Policy Analysis: Den Haag, The Netherlands, 2014; pp. 1-94.

131. Maslow, A. Motivation and Personality, 2nd ed.; Harper \& Bros: New York, NY, USA, 1954.

132. Pech, W.J. Behavioral Economics and The Basic Income Guarantee. Basic Income Stud. 2010, 5. [CrossRef]

133. Gagné, M.; Deci, E.L. Self-determination theory and work motivation. J. Organ. Behav. 2005, 26, 331-362. [CrossRef]

134. Thomas, K. Intrinsic Motivation at Work: What Really Drives Employee Engagement, 2nd ed.; Barrett-Kohler Publishers: San Francisco, CA, USA, 2009.

135. White, R. Motivation reconsidered: The concept of competence. Psychol. Rev. 1959, 66, 297-333. [CrossRef]

136. Pike, D.H. Drive: The Surprising Truth about What Motivates Us; Riverhead Books: New York, NY, USA, 2009.

137. Kirk, J.; Wall, C. Work and Identity: Historical and Cultural Contexts; Palgrave Macmillan: New York, NY, USA, 2011.

138. Maestas, N. Back to work: Expectations and realizations of work after retirement. J. Hum. Resour. 2010, 45, 718-748. [CrossRef] [PubMed]

139. Simpson, W.; Stevens, H. The Impact of Converting Federal Non-Refundable Fax Credits into Refundable Credits; SPP Research Papers 8; The School of Public Policy: Calgary, AB, Canada, 2015.

140. Aceytuno, M.T.; de Paz-Báñez, M.A.; Sánchez-López, C. Assessing the impact of the implementation of Universal Basic Income on entrepreneurship. J. Bus. Ventur. Submitted for publication. Forthcoming.

141. Yun, J.J.; Park, K.; Hahm, S.D.; Kim, D. Basic Income with High Open Innovation Dynamics: The Way to the Entrepreneurial State. J. Open Innov. Technol. Mark. Complex. 2019, 5, 41. [CrossRef]

142. Bidadanure, J.U. The Political Theory of Universal Basic Income. Annu. Rev. Political Sci. 2019, 22, 481-501. [CrossRef]

143. Graeber, D. Bullshit Jobs: A Theory; Simon \& Schuster: New York, NY, USA, 2018.

144. Standing, G. The Precariat. The New Dangerous Class; Bloomsbury: London, UK; New York, NY, USA, 2011. 
145. Brynjolfsson, E.; McAfee, A. The Second Machine Age: Work, Progress and Prosperity in a Time of Brilliant Technologies; W.W. Norton: New York, NY, USA, 2014.

146. Frey, C.B.; Osborne, M. Technological Change and New Work. Policy Network, 15 May 2014.

147. Author, D.; Salmons, A. Does Productivity Growth Threaten Employment? In Proceedings of the Forum ECB, Sintra, Portugal, 19 June 2017.

148. We define systematic review protocol in this context as an explicit and planned scientific "roadmap" before its inception detailing the rational and planned methodological and analytical approach of the review. We have also followed BMJ 2015, 349, g7647. Available online: http://www.prisma-statement.org/Extensions/Protocols (accessed on 2 January 2015). [CrossRef]

Publisher's Note: MDPI stays neutral with regard to jurisdictional claims in published maps and institutional affiliations.

(C) 2020 by the authors. Licensee MDPI, Basel, Switzerland. This article is an open access article distributed under the terms and conditions of the Creative Commons Attribution (CC BY) license (http://creativecommons.org/licenses/by/4.0/). 